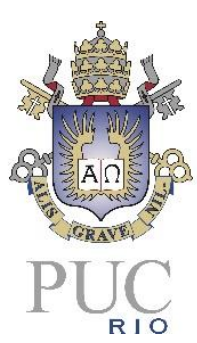

PONTIFÍCIA UNIVERSIDADE CATÓLICA DO RIO DE JANEIRO

LUCAS PAES FORTES

A criação do plano de negócios da SunFor, empresa de venda de kits fotovoltaicos para produção de energia solar

Rio de Janeiro

2020 


\title{
A criação do plano de negócios da SunFor, empresa de venda de kits fotovoltaicos para produção de energia solar
}

\author{
Trabalho de Conclusão de Curso, \\ apresentado ao programa de graduação \\ em Administração da PUC-Rio como \\ requisito parcial para a obtenção do título \\ de graduação em Administração
}

Orientador: Prof. Henrique Castro Martins

Rio de Janeiro 


\section{A criação do plano de negócios da SunFor, empresa de venda de kits fotovoltaicos para produção de energia solar}

\begin{abstract}
Trabalho de Conclusão de Curso, apresentado ao programa de graduação em Administração da PUC-Rio como requisito parcial para a obtenção do título de graduação em Administração
\end{abstract}

Rio de Janeiro, 21 de junho de 2020.

BANCA EXAMINADORA

Prof. (Nome do orientador)

Afiliações

Prof. (Nome do professor avaliador)

Afiliações

Prof. (Nome do professor avaliador)

Afiliações 


\section{AGRADECIMENTOS}

Agradeço a todos que torceram por mim em toda minha vida, especialmente ao meu pai que sempre me apoiou e me proporcionou a oportunidade de estudar nessa faculdade, a minha mãe que não está presente fisicamente nesse plano mas me deu muito carinho e amor quando esteve aqui, ao meu irmão que sempre foi referência profissional e abraçou a ideia de criar uma empresa e ser meu sócio nessa empreitada, a minha irmã que desde a adolescência me inspirou a se dedicar aos estudos, e a toda minha família que foi fonte de inspiração para eu chegar até aqui. 
Fortes, Lucas. A elaboração do plano de negócios de uma empresa de venda de kits fotovoltaicos e desenvolvimento projetos para produção de energia solar. Rio de Janeiro, 2018. 29 p. Trabalho de Conclusão de Curso - Departamento de Administração. Pontifícia Universidade Católica do Rio de Janeiro.

\section{RESUMO}

Esse trabalho consiste no desenvolvimento de um Plano de Negócios para uma empresa que atuará no mercado de energia renovável através do desenvolvimento de projetos e venda de sistemas denominados "kits" de geração de energia fotovoltaica. Esses sistemas permitem ao consumidor, gerar a própria energia de forma simples, limpa e mais barata. O potencial brasileiro de geração deste tipo de energia é muito grande devido à alta incidência de raios solares e foi muito pouco explorado. Esse fator de alto potencial de geração e pouco desenvolvimento incentiva o empreendedor a explorar esse mercado, e o plano de negócios ajuda o mesmo a pôr em prática a ideia e buscar informações que alimentem o negócio. $\mathrm{O}$ plano de negócios aqui desenvolvido apresentará uma profunda analise do mercado, o planejamento estratégico, plano de marketing, plano operacional e financeiro da empresa.

Palavras-chave: Plano de negócios, energia renovável, energia solar, matriz energética, fontes de energia 
Paes Fortes, Lucas. The elaboration of the business plan of a company that sells photovoltaic kits and develop projects for the production of solar energy. Rio de Janeiro, 2018. 29 p. Trabalho de Conclusão de Curso - Departamento de Administração. Pontifícia Universidade Católica do Rio de Janeiro.

\begin{abstract}
This work consists in the development of a Business Plan for a company that will act in the renewable energy market through the development of projects and sale of systems called photovoltaic power generation kits. These systems allow the consumer to generate their own energy simply, cleanly and cheaply. The Brazilian potential for generating this type of energy is very large due to the high incidence of solar rays and has been little explored. This factor of high potential of generation and little development encourages the entrepreneur to explore this market, and the business plan helps to put the idea into practice and seek information that fuels the business.

The business plan developed here will present a thorough analysis of the market, strategic planning, marketing plan, operational and financial plan of the company.

Key-words

Business plan, renewable energy, solar energy, energy matrix, energy sources
\end{abstract}




\section{LISTA DE FIGURAS}

Figura 1. Radiação solar no plano horizontal, média anual e diária .........................12

Figura 2. Radiação solar diária no Brasil.....................................................13

Figura 3. Irradiação solar média anual - Brasil / Alemanha. ....................................14

Figura 4. Matriz elétrica brasileira em 2019..................................................15

Figura 5.Projeção da Matriz elétrica brasileira para 2040 ......................................19

Figura 6.Crescimento da capacidade instalada solar fotovoltaica no Brasil ..............19

Figura 7-A Relação Entre as Fases do Processo de um ProjetoErro! Indicador não definido.

Figura 8- A Relação Entre as Fases do Processo de um Projeto ............................25

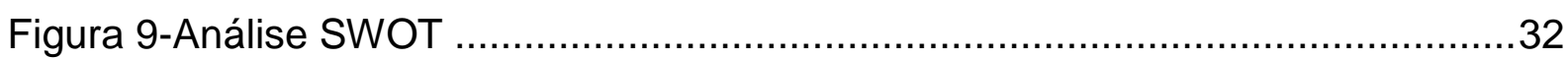




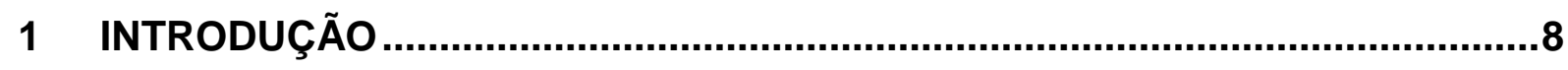

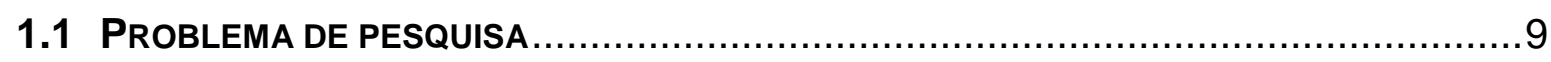

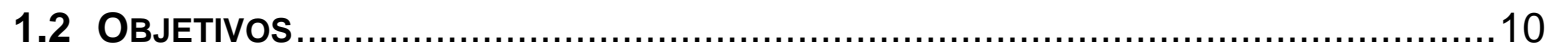

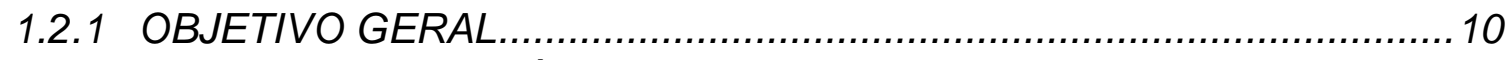

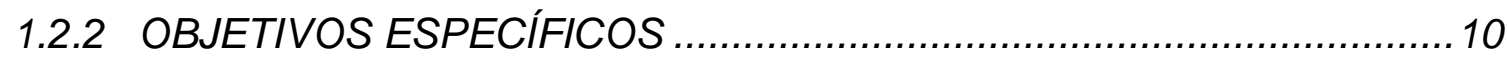

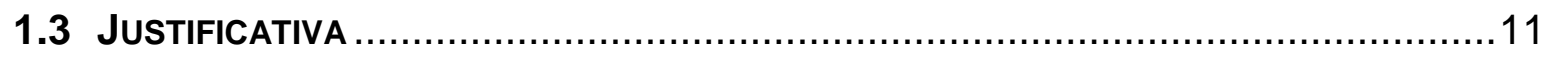

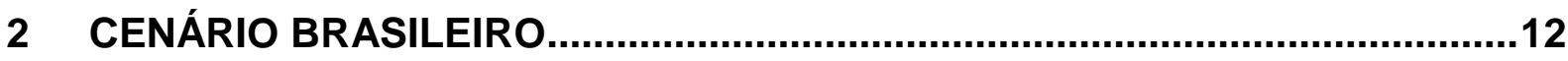

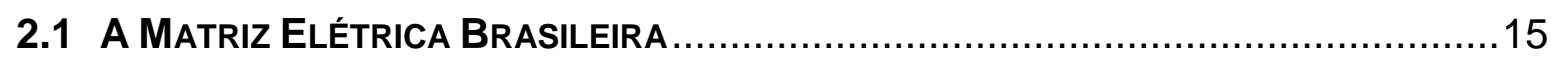

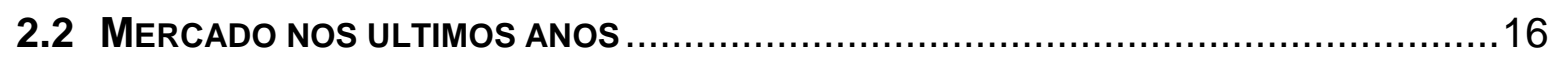

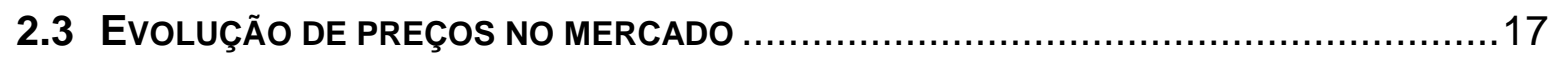

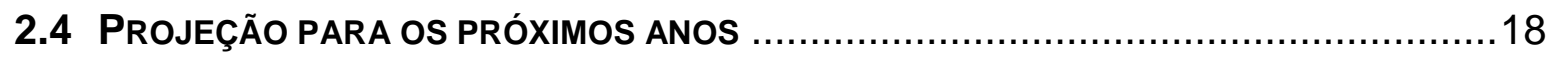

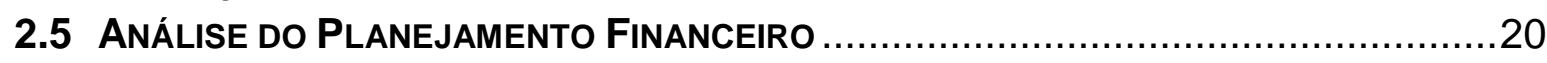

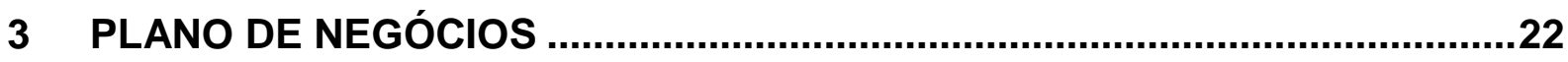

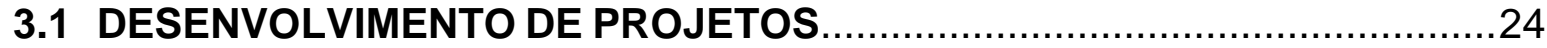

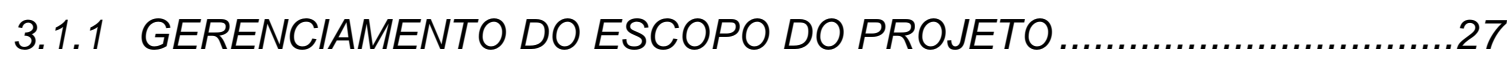

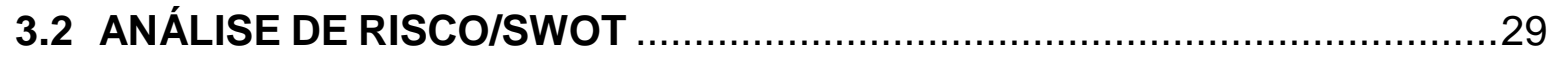

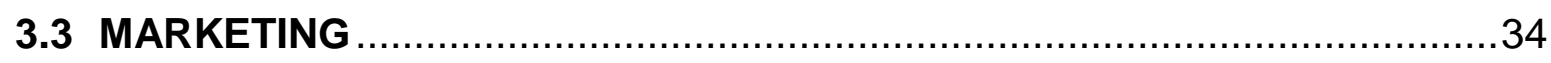

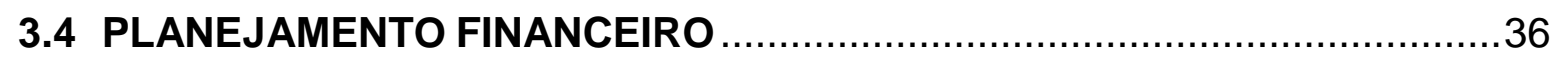

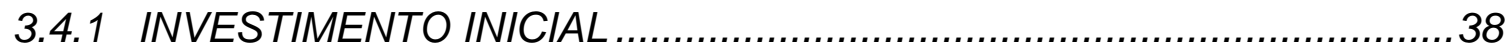

3.4.2 FUNCIONÁRIOS E REMUNERAÇÃO ................................................40

3.4.3 PREÇOS E RECEITAS ESTIMADAS ................................................ 41

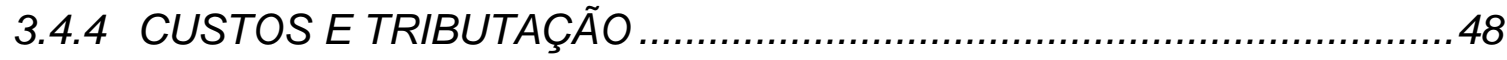

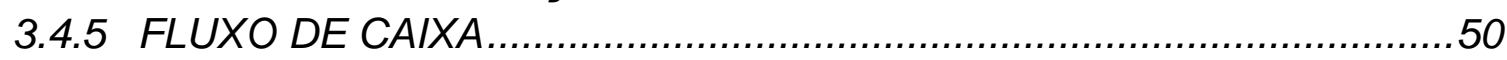

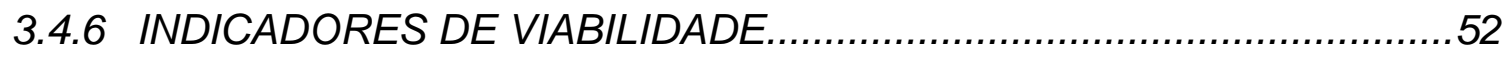

4 CONCLUSÃO

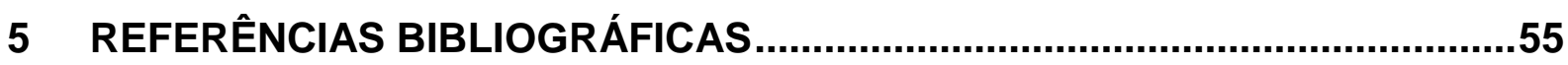




\section{INTRODUÇÃO}

O Brasil é um país reconhecido por seus recursos naturais, sua terra fértil, ventos de qualidade, alta irradiação solar e grandes reservas de água doce. Todos esses fatores favorecem a geração de energia renovável... porém não possui qualidade na sua distribuição e nem boa divisão entre as fontes de geração, onde a geração hidráulica domina o cenário fazendo com que os brasileiros fiquem "reféns" dessa fonte de geração. Por anos conseguimos observar uma grande falha no sistema de distribuição que gera prejuízos enormes aos cofres públicos além dos transtornos causados ao contribuinte que não tem o retorno dos impostos que paga. Um episódio de nossa história recente mais conhecido como "apagão do ano de 2001" afetou todo o território brasileiro e expôs aos brasileiros as consequências dessa falha de planejamento que segundo dados do Tribunal de Contas da União gerou um prejuízo de 45,2 bilhões de reais.

Neste cenário podemos destacar a energia solar fotovoltaica, que deve proporcionar grande parte da solução para uma matriz elétrica diversificada, limpa, segura, economicamente viável e abundante.

O objetivo deste trabalho é montar um plano de negócios de uma empresa de projetos de energia fotovoltaica onde será detalhado o mapeamento do cenário elétrico brasileiro, os planos de operação, marketing e plano financeiro. Isso ajudará a empresa analisar de uma forma ampla todos os fatores que interferem no alcance das metas para o futuro da companhia.

A principal contribuição deste trabalho é para todos os stakeholders da cadeia produtiva do setor de energia do Brasil, o estudo visa contribuir com a diversificação da matriz energética brasileira que nos últimos anos tem apontado grande crescimento das energias renováveis 


\subsection{PROBLEMA DE PESQUISA}

O Brasil é um país que sofre repetidamente com aumentos na conta de luz. O consumidor vem pagando contas cada vez mais caras mesmo com a construção de novas usinas hidrelétricas que teoricamente serviram para aumentar a oferta e reduzir o preço. Isso ocorre principalmente quando chove menos e a "bandeira vermelha do sistema é acionada". A principal causa desse problema na sua raiz é a estrutura da matriz elétrica brasileira que é composta em sua maioria por Hidrelétricas e Carvão. Isso faz com que o país dependa muito das chuvas para que reservatórios fiquem abastecidos e gerem energia. Portanto quando não ocorrem essas chuvas o país demanda por uma outra fonte de energia (mais cara) para suprir a falta do fornecimento. É importante ressaltar que pela sazonalidade, na época que chove menos, é a mesma época que tem mais sol e mais vento ao mesmo tempo, principalmente nas regiões norte e nordeste. É por esse motivo que a diversificação da matriz energética se faz necessária, principalmente no Brasil.

Vale ressaltar também, que hoje em dia o consumidor não sabe de onde vem a energia que ele consome e só sabe qual o valor que irá pagar somente quando a conta de energia chega no final do mês.

Hoje com a geração de energia solar o consumidor consegue saber de onde vem a energia, controlar o consumo e reduzir em até $95 \%$ sua conta de luz com a geração solar conectado à rede (On Grid), os $5 \%$ que não são abatidos da conta são referentes a "taxa" que é cobrada pela distribuidora de energia para que se possa utilizar a rede para injetar os créditos que serão consumidos no período noturno, quando não há geração de energia. Esse desconto pode chegar em até 100\% com o uso de baterias (Off grid), pois assim o consumidor armazenará o excedente produzido de dia nas baterias e consumirá direto da bateria de noite, sem conexões na rede elétrica e sem taxas de distribuidora.

Um grande problema enfrentado por empresas do setor é o fato de que os empresários brasileiros não possuem organização nem planejamento para o tempo de payback do projeto, hoje o período de recuperação do investimento é de 4 anos em média. No contexto brasileiro atual (incerteza política e crise econômica) é difícil encontrar empresários que tenha metas e planejamentos para mais de 4 anos, além 
de capital para o investimento. Dentro desse contexto qual seria a viabilidade de se criar uma empresa de energia solar no Brasil?

\subsection{OBJETIVOS}

\subsubsection{OBJETIVO GERAL}

Avaliar a viabilidade econômico-financeira da criação de uma empresa que forneça soluções inteligentes em energia solar.

\subsubsection{OBJETIVOS ESPECÍFICOS}

- Mapear os clientes que são grandes consumidores de energia e os locais com melhor potencial para geração

- Identificar clientes que estejam insatisfeitos com o fornecimento de energia

- Identificar os clientes que possuem as melhores condições (espaço) para instalações fotovoltaicas.

- Analisar as diferentes demandas de clientes e fornecer as melhores soluções para cada tipo de cliente, destacando o tempo de recuperação do investimento, valor da economia gerada e o quanto isso é sustentável

- Fechar negócio

- Realizar a instalação, legalização junto à distribuidora de energia e manutenção do sistema 


\subsection{JUSTIFICATIVA}

O desenvolvimento do plano de negócios ajuda aos empreendedores a alcançar os objetivos que foram traçados durante a criação da empresa, serve também como um modelo de negócios a ser seguido durante o processo de amadurecimento da empresa para que o objetivo final seja alcançado mesmo com as ocasiões desfavoráveis que possam ocorrer.

O plano de negócios reúne informações importantes de como o negócio deverá ser desenvolvido e como a empresa irá atuar no mercado. Pode ser utilizado como ferramenta de marketing interno e como forma de atrair ou comunicar o conteúdo a investidores.

O plano de negócios da empresa também contribuirá para todo o setor de geração fotovoltaica mostrando características do mercado, produtos que serão comercializados, forças e fraquezas do empreendimento, projeções de estratégias operacionais e resultados financeiros, concorrentes e serviços a serem prestados. Esses dados são úteis para toda a cadeia produtiva do setor e ajudará não só aos sócios internamente, mas também aos possíveis investidores, como citado anteriormente.

O plano prevê a criação de uma empresa em um mercado muito novo e que tem muito a se desenvolver devido ao potencial que o Brasil possui para esse setor. Este estudo resultará em um material que poderá ser estudado no futuro e servirá como complemento para examinar a evolução do mercado brasileiro de energia fotovoltaica. 


\section{CENÁRIO BRASILEIRO}

Segundo dados da IEA (Agência Internacional de Energia), a energia solar fotovoltaica poderá representar um terço da produção global de energia elétrica do mundo até 2060 (IEA, 2011). Estudos realizados pela Bloomberg mostram que a energia solar fotovoltaica representará mais de $25 \%$ da matriz elétrica global em menos de 25 anos (BNEF, 2016b). Com isso, a energia fotovoltaica tem o potencial para ser a maior fonte de eletricidade no mundo em longo prazo, devido à abundância e à distribuição do recurso solar no planeta, à constante redução dos custos da tecnologia (histórico e projeção) e às melhorias em eficiência de materiais e conversão de energia. Isso sem mencionar a tendência global em direção às fontes de energia limpas e sustentáveis. A figura a seguir mostra a distribuição de radiação solar em todo o mundo.

É possível notar regiões de maior potencial tais como África, Austrália, Emirados Árabes, Irã, parte da China, parte dos Estados Unidos, Chile, México, Brasil, Argentina, Bolívia, Peru, dentre outros.

Figura 1. Radiação solar no plano horizontal, média anual e diária

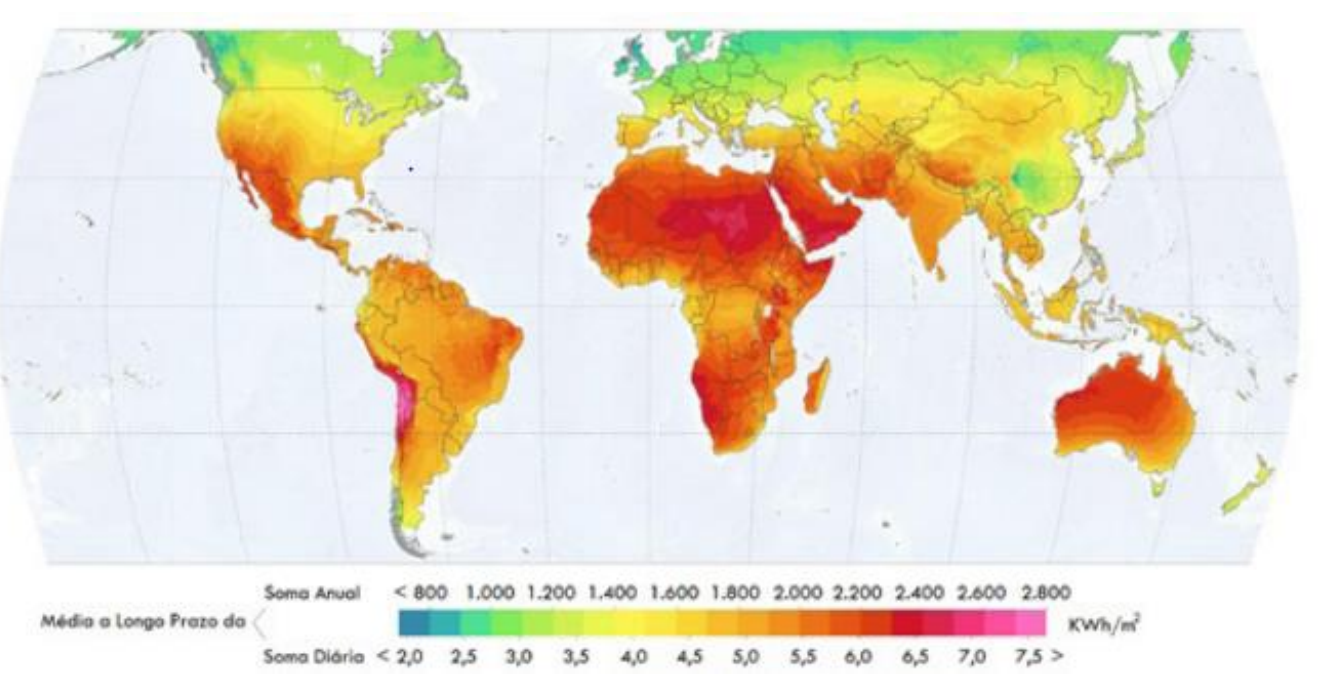

Fonte: Solargis 2016

Em um país ensolarado como o Brasil, este potencial é ainda mais possível e viável. De acordo com as projeções da Bloomberg New Energy Finance (2016), a energia fotovoltaica representará por volta de $32 \%$ da matriz elétrica brasileira, 
passando da fonte com menor representatividade na matriz em 2016 para a fonte com a maior representatividade em 2040, com capacidade instalada entre 110 e 126 GWac.

Conforme dados do Atlas Brasileiro de Energia Solar do Instituto Nacional de Pesquisas Espaciais (INPEs) (Pereira, 2006), o Brasil apresenta um excelente recurso solar, que varia entre 1.500 e $2.350 \mathrm{kWh} / \mathrm{m} 2 / a n o$. É um recurso bem distribuído ao redor do país, superior ao verificado em países como a Alemanha (900 a $1.250 \mathrm{kWh} / \mathrm{m} 2 / \mathrm{ano}$ ), a França (900 a $1.650 \mathrm{kWh} / \mathrm{m} 2 / \mathrm{ano}$ ) e até mesmo a Espanha (1.200 a $1.850 \mathrm{kWh} / \mathrm{m} 2 / \mathrm{ano})$. Os estados com maiores índices de radiação solar no Brasil são Bahia, Piauí, Paraíba, Rio Grande do Norte, Ceará, Tocantins, Goiás, Minas Gerais e São Paulo. (Sebrae, 2016)

Figura 2. Radiação solar diária no Brasil.

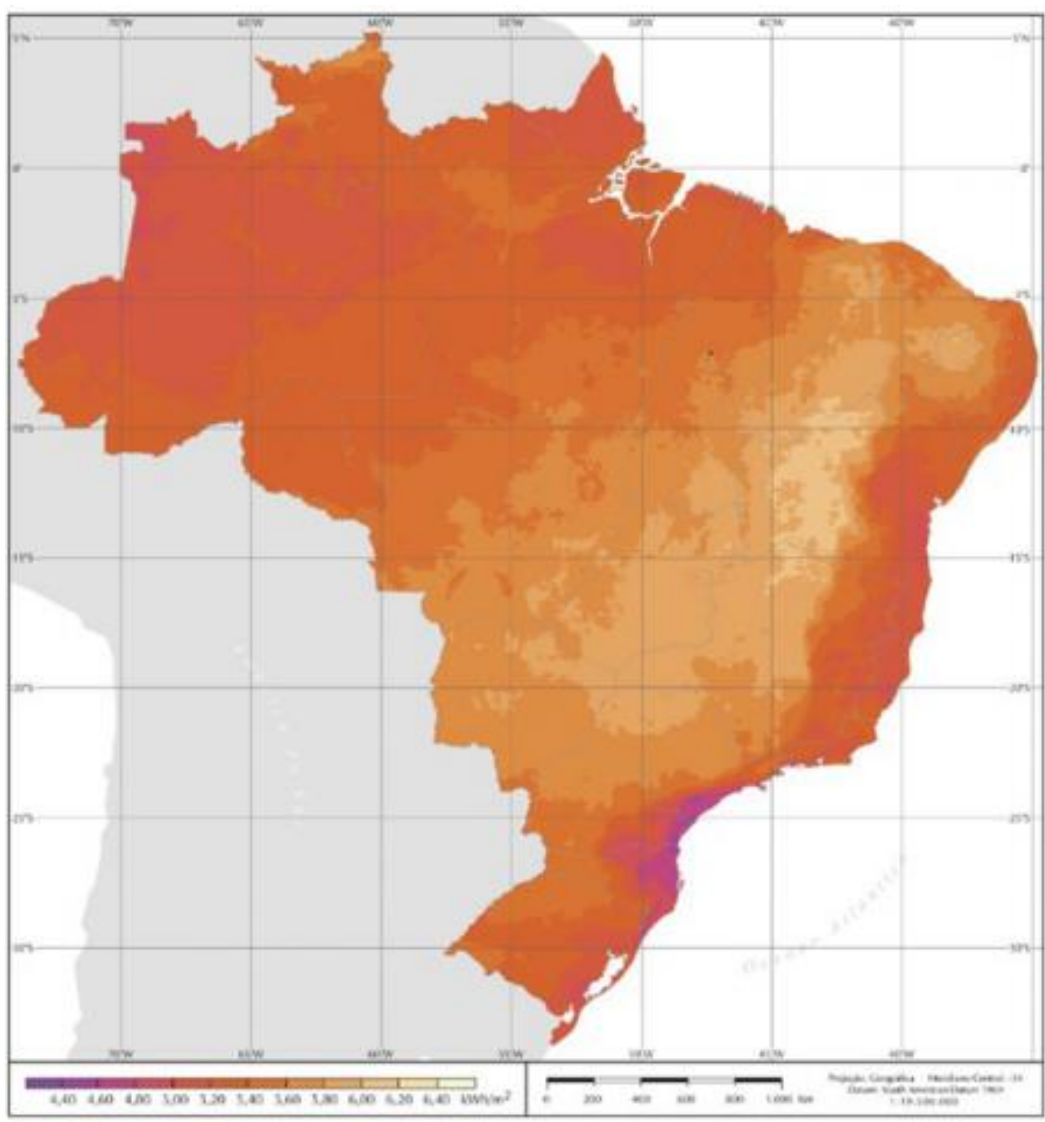

Fonte: Pereira, 2006 
Com relação à geração distribuída solar fotovoltaica, um mapeamento da EPE aponta um potencial de mais de 164 GW apenas para os telhados de domicílios brasileiros.

Ao comparar o Brasil com outros países mais desenvolvidos que possuem muito menos irradiação solar, é possível perceber claramente o quanto do potencial brasileiro está sendo desperdiçado. Ao analisar a próxima figura, é possível perceber que a região menos ensolarada do Brasil apresenta índices solares (em torno de $1642 \mathrm{kWh} / \mathrm{m}^{2}$ ) muito acima dos valores apresentados na área de maior incidência solar da Alemanha (cerca de $1300 \mathrm{kWh} / \mathrm{m}^{2}$ ) (SALAMONI E RÜTHER, 2007). No entanto, apesar de apresentar melhores condições climatológicas, na comparação de mercado, o Brasil está muito atrás do país europeu que é líder mundial em produção de energia fotovoltaica (cerca de $20 \mathrm{GW}$ ). Nota-se que o Brasil, com grande potencial para aproveitamento de energia solar, possui uma importante vantagem sobre a Alemanha, no que diz respeito aos níveis de radiação solar.

Figura 3. Irradiação solar média anual - Brasil / Alemanha.

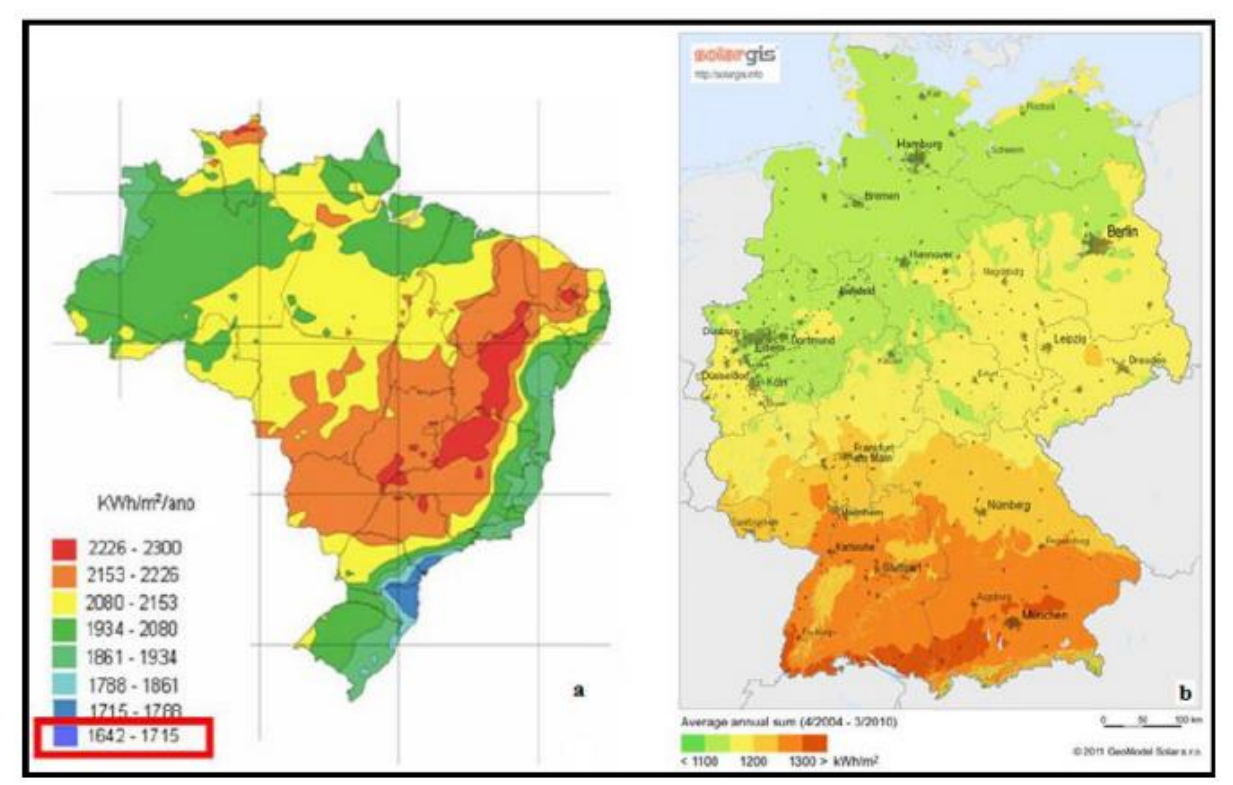

Fonte: Salamoni e Ruter, 2007 / Geomodel Solar

Porém se comparar a capacidade instalada nos dois países é possível perceber a grande vantagem da Alemanha, onde políticas públicas adotadas a mais de 8 anos atrás disparam o país na liderança de geração de energia fotovoltaica mesmo com todo seu território tendo um potencial muito baixo de geração. A meta 
do país europeu é chegar a $80 \%$ da produção da energia do país sendo renovável, atualmente está perto de $30 \%$. Dentre muitas medidas, a nova política de geração de energia alemã determinou que a preferência para entrar na rede é das energias renováveis. Isso significa que o governo só começa a consumir energia gerada nas usinas fósseis após ter consumido, primeiro, a produzida pelo sol e vento.

\subsection{A MATRIZ ELÉTRICA BRASILEIRA}

No final de 2019 a matriz elétrica brasileira era formada no seu total por 175 GW de capacidade instalada, onde 18,5\% eram de fontes renováveis (sem contar hidrelétricas), a eólica é a que possui maior representação com 15,5 GW, em seguida a Biomassa com 14,8 GW, a solar fotovoltaica ganhou espaço dos últimos anos e saltou de 0,023 GW em 2016 para 2,2 GW em 2019 (Sem incluir os projetos de GD). Com relação aos projetos de GD, a disseminação de capacidade instalada dos projetos conectados à rede elétrica é devida à Resolução Normativa (REN) ANEEL Número 482 de 17 de abril de 2012 (REN 482), vigente no Brasil desde 2012, e posteriormente atualizada pela Resolução Normativa ANEEL Número 687 de 24 de novembro de 2015 (REN 687), conhecida como net metering, ou Sistema de Compensação de Energia Elétrica. 


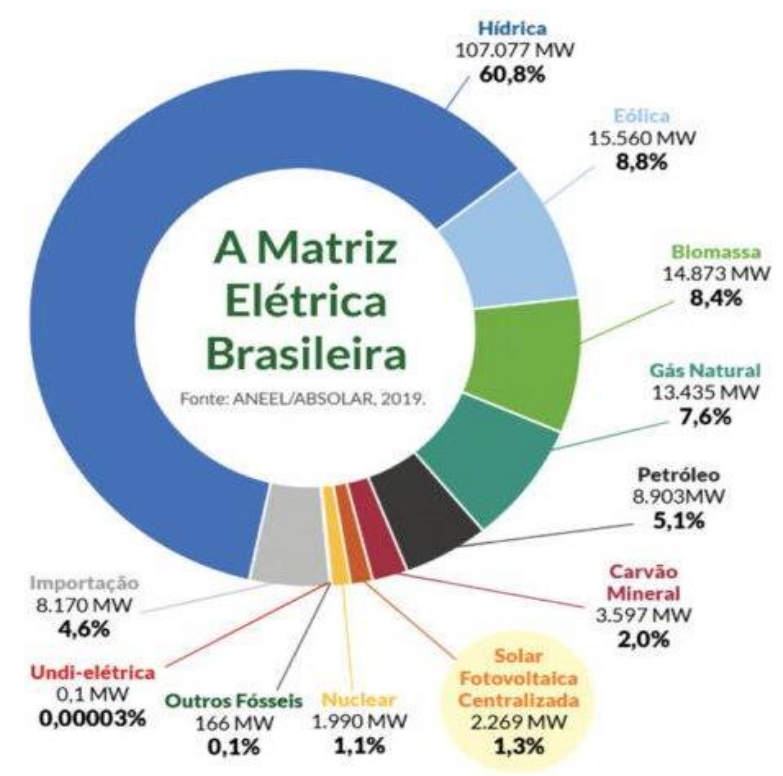

. Fonte: Aneel, 2019.

\subsection{MERCADO NOS ULTIMOS ANOS}

O mercado brasileiro de energia fotovoltaica teve seu início no ano de 2012 após a ANEEL - Agência Nacional de Energia Elétrica - estabelecer algumas regras para a microgeração e a minigeração distribuída de energia solar por particulares. Antes dessa data a instalação fotovoltaica só poderia ser feita de duas formas: consumindo a energia produzida pelos painéis no momento de geração (quando houvesse sol) ou através do uso de baterias para que a energia produzida pelos painéis durante os dias ensolarados fosse armazenada para ser usada posteriormente no período em que a energia não fosse produzida. Esse fato fazia com que a instalação se tornasse inviável pois a demanda noturna não teria como ser suprida sem a instalação de baterias e os custos seriam muitos altos para armazenar a energia.

Através da Resolução Normativa $\mathrm{n} .-482$ (primeiro ato regulatório a permitir o sistema de compensação), a energia produzida por painéis fotovoltaicos instalados em telhados gera créditos que podem ser compensados, abatendo assim os custos da conta de luz junto as distribuidoras. Este sistema de compensação é conhecido mundialmente como net-metering. Apesar de não se tratar essencialmente de um incentivo, ele representa o marco inicial da geração solar distribuída no Brasil. 
Após 3 anos da R.N. 482, foi necessário rever algumas regras e fazer ajustes para que a geração fotovoltaica (principalmente a distribuída) pudesse ser melhor aproveitada. Com a Resolução Normativa № 687 de 2015, a ANEEL estabeleceu novas regras que passaram a valer desde $1^{\circ}$ de Março de 2016. Podemos destacar alguns pontos da resolução como a mudança dos limites de capacidade instalada para micro- e minigeração, a redução na burocracia de conexão dos sistemas, e a ratificação do "autoconsumo" remoto, que possibilita ao consumidor, gerar créditos em outra localidade que não seja a de geração da energia ( desde que esteja registrada sob o mesmo CPF ou CNPJ).

Dentre alguns incentivos do governo, é possível destacar a isenção do imposto sobre circulação de mercadorias e serviços (ICMS) em geradores fotovoltaicos, que possibilitou uma redução do payback nos projetos de energia solar fotovoltaica, contribuindo muito para desenvolvimento do setor. Ainda há projetos de lei que incentivam a instalação de módulos fotovoltaicos, porém estão parados na câmara.

\subsection{EVOLUÇÃO DE PREÇOS NO MERCADO}

Uma grande preocupação de pessoas interessadas em instalar kits de energia solar em suas propriedades é a questão dos preços dos equipamentos. Muitos desses possíveis clientes têm a percepção de alguns anos atrás em que o payback de um projeto de energia fotovoltaica se dava em 10 anos, e de que o mercado e a tecnologia ainda vão evoluir, portanto, deixam de lado o interesse pelo tema. O principal componente dos sistemas de energia solar é o módulo fotovoltaico, e o custo deste, impacta diretamente o preço final. Segundo o NREL (National Renewable Energy Laboratory, 2017) o preço dos módulos fotovoltaicos caiu incrivelmente, variando de \$1,80/watt em 2010, até \$0,35/watt em 2017 para módulos de silício policristalino.

Figura 5. Preço histórico dos módulos fotovoltaicos 


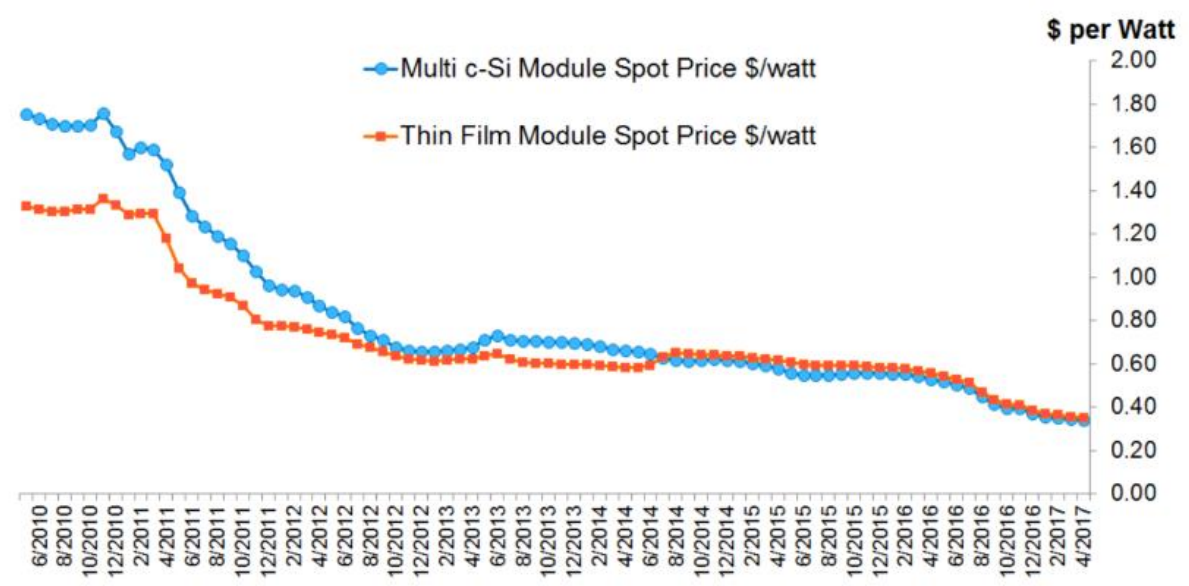

. Fonte NREL, 2017.

É possível perceber uma queda bastante acentuada nos preços de 2010 a 2012, e após isso o custo dos módulos fotovoltaicos atingiu um patamar relativamente estável. Segundo Lucas Lau (Sharenergy Brasil, 2017), essa queda, obtida no começo da década, foi alcançada através do grande esforço em melhoria dos processos de fabricação e aumento da eficiência dos módulos. Nos anos seguintes essa eficiência foi se aproximando de seu limite teórico, dificultando as reduções efetivas nos custos de produção destes equipamentos. Já a queda observada entre o ano de 2016 e 2017 é explicada por variações cambiais entre o Dólar americano e o Yuan chinês.

No Brasil o cenário é diferente, com uma queda mais acentuada nos preços dos kits fotovoltaicos principalmente em 2017 e 2018. Essa redução ocorreu devido à entrada de novos players no mercado nacional, diminuindo a margem dos fabricantes e distribuidores ao comercializar o produto no país. Considerando que o mercado vem se consolidando no país e a tecnologia já se encontra bem desenvolvida, é difícil prever qual será futuro para o preço deste equipamento, que deve oscilar muito mais por razões de mercado e cambiais do que por alteração nos custos de produção.

\subsection{PROJEÇÃO PARA OS PRÓXIMOS ANOS}


A sociedade está presenciando o movimento em direção às renováveis em todo o mundo, visto que a energia renovável está cada vez mais competitiva, seus projetos são construídos rapidamente (especialmente comparados aos fósseis e hídricos) - atendendo à crescente demanda por energia elétrica no país - além de utilizarem 200 vezes menos água do que as fontes fósseis de energia (IRENA, 2015). De acordo com as projeções da Bloomberg New Energy Finance, a energia fotovoltaica representará 32\% - entre 110 e 126 GWac - da matriz elétrica brasileira em 2040, passando da fonte com menor representatividade na matriz para a fonte com a maior representatividade, uma verdadeira revolução (BNEF, 2015b).

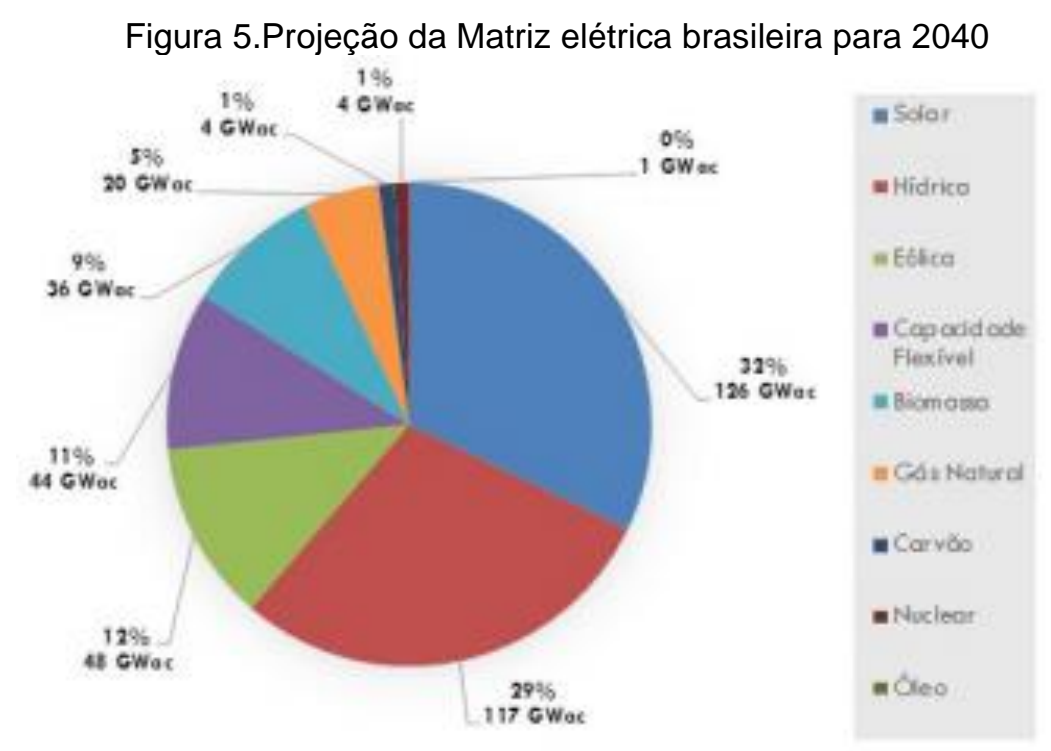

. Fonte: BNEF, 2016.

Supondo o cenário mais conservador de 110 GWac de capacidade solar fotovoltaica instalada no país em 2040 , aproximadamente $75 \%$ será proveniente de projetos de geração distribuída, e o resto de geração centralizada. Essa projeção da Bloomberg para a geração distribuída em longo prazo está próxima à projeção do relatório "Demanda de Energia 2050" da Empresa de Pesquisas Energéticas (EPE) (EPE, 2016c), que projeta entre $50 \mathrm{GWp}$ e $82 \mathrm{GWp}$ de geração distribuída no Brasil até 2040, conforme indicado na tabela a seguir para dois diferentes cenários.

Ainda, segundo a ANEEL, até 2024 cerca de 1,2 milhão de residências no país vão contar com eletricidade produzida por sistemas de geração distribuída (Portal Brasil, 2016). 


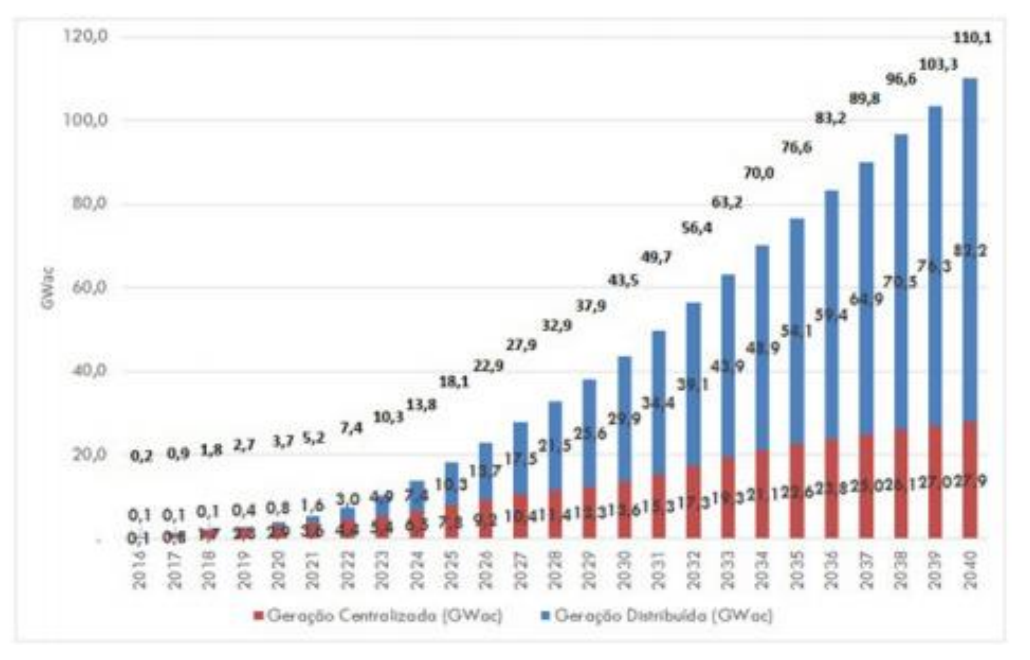

Fonte: BNEF, 2015

\subsection{ANÁLISE DO PLANEJAMENTO FINANCEIRO}

Após a análise do mercado e das projeções futuras é possível destacar os fundamentos de administração financeira que serão utilizados para o desenvolvimento do plano de negócios da empresa. Inicialmente é preciso ter uma estimativa do investimento inicial a ser feito, estoque, investimento pré-operacional em capital de giro, despesas de legalização entre outros. Será desenvolvida uma projeção de demonstração de resultados do exercício (DRE) que mede o desempenho de período, normalmente um trimestre ou um ano. (ROSS, WESTERFIELD e JORDAN, 2013). Após isso serão avaliadas as informações financeiras mais importantes que podem ser garimpadas nas demonstrações financeiras; o fluxo de caixa. Fluxo de caixa é a diferença entre a quantidade de dinheiro que entra e a quantidade de dinheiro que sai. Também associado ao fluxo de caixa, será calculado o valor presente líquido (VPL) que é a fórmula econômicofinanceira capaz de determinar o valor presente de pagamentos futuros descontados a uma taxa de juros apropriada, menos o custo do investimento inicial. (DA MOTTA e CALÔBA, 2002). O período de retorno do investimento (payback) também será usado na análise do investimento para saber o período necessário para recuperar o investimento inicial.

Como uma alternativa mais importante com relação ao valor presente líquido(VPL) existe a taxa interna de retorno (TIR). Com a TIR será analisada uma 
única taxa de retorno que resuma os méritos do projeto, sendo uma taxa "interna" ela depende apenas dos fluxos de caixa do investimento e não de taxas oferecidas no mercado. 


\section{PLANO DE NEGÓCIOS}

O modelo de negócios não apenas se restringe a áreas de administração de empresas, como também podem contribuir para os mais diversos âmbitos com os quais se pretende trabalhar, dentro de um universo que sofre influências das transformações sociais e, por isso podem adequar as orientações às suas particularidades organizacionais.

O conceito pode se tornar uma linguagem comum que permita a você
descrever e manipular facilmente Modelos de Negócios para criar novas
estratégias. Sem essa linguagem fica difícil desafiar sistematicamente as
suposições sobre determinado Modelo de Negócios e inovar com sucesso.
Acreditamos que um Modelo de Negócios pode ser melhor descrito com
nove componentes básicos, que mostram a lógica de como uma
organização pretende gerar valor. Os nove componentes cobrem as quatro
áreas principais de um negócio: clientes, oferta, infraestrutura e viabilidade
financeira. O Modelo de Negócios é um esquema para a estratégia ser
implementada através das estruturas organizacionais dos processos e
sistemas. (OSTERWALDER e PIGNEUR, 2011, p. 15).

Os nove elementos mencionados anteriormente são: Segmentos de Clientes, Proposta de Valor; Canais; Relacionamento com o Cliente; Fontes de Receita; Recursos Principais; Atividades-chave; Parcerias Principais; e Estrutura de Custo.

O tópico "Segmento de Clientes" consiste em definir qual o grupo, públicoalvo, e consumidores que a organização pretende alcançar, o que na área da tecnologia de energia solar, em geral, consiste em um público mais consciente, que já vivencia as tecnologias de maneira bem intensa, considerando que seu contato com o ramo já se sustenta desde a inserção das energias sustentáveis, na sociedade moderna. (OSTERWALDER e PIGNEUR, 2011). Em geral pessoas físicas e empresas que desejam obter energia elétrica por meio de painéis fotovoltaicos. Os projetos podem ser instalados em residências, comércios ou empresas que disponibilizarem espaço para a instalação dentro da área de cobertura da concessionária de energia do consumo.

As "Propostas de Valores" assumem a característica mais financeira da temática, podendo inclusive angariar elementos da pesquisa de valor de mercado, enfim, aspectos que são imprescindíveis também para que os clientes percebam a 
viabilidade em consumir os produtos, ou contratar os serviços de determinada instituição, no sentido de que seja viável o custo $\mathrm{x}$ benefício. (OSTERWALDER e PIGNEUR, 2011).

Os "Canais" dizem respeito às formas de distribuição de produtos, ou de fornecimento de atendimento aos clientes, que são realizadas pelo contato que a empresa se dispõe a realizar, com os seus consumidores. (OSTERWALDER e PIGNEUR, 2011).

O "Relacionamento com o Cliente" consiste na maneira que a empresa utiliza os canais de comunicação, como ocorrem os seus diálogos com o seu público, e de que maneira é possível receber um feedback no que diz respeito ao grau de satisfação dos mesmos. Para isso a empresa disponibilizará um SAC em suas mídias sociais e site para que os clientes sintam-se bem atendidos. É importante, ainda, considerar os departamentos, e segmentos com os quais se pretende trabalhar, a fim de desenvolver um trabalho voltado para as especificidades de cada área, considerando que os indivíduos, conforme estão inseridos em um ramo, automaticamente reagirão de maneiras diferentes e, por isso, é importante adequar o tratamento, e a comunicação. (OSTERWALDER e PIGNEUR, 2011).

As "Fontes de Receita", como o próprio nome remete, diz respeito aos lucros, rendimentos, enfim, aos valores financeiros que a instituição estará recebendo através da venda dos painéis, e também investindo, na intenção de garantir o sucesso da corporação, e também no sentido de poder oferecer propostas viáveis e compatíveis com o perfil da sua demanda como manutenção dos equipamentos e ofertas de novas tecnologias compatíveis com os projetos. (OSTERWALDER e PIGNEUR, 2011).

Os "Recursos Principais" compreendem os recursos, tanto humanos, quanto materiais que estão disponíveis na organização e que, consequentemente, foram previamente estabelecidos em seu planejamento, de forma que seja possível viabilizar os elementos ativos para oferecer e entregar os elementos previamente descritos. (OSTERWALDER e PIGNEUR, 2011).

As "Atividades-chave", por sua vez, são as funções desenvolvidas pela empresa, e que são executadas no seu cotidiano, principalmente no que diz respeito a produção, atendimento ao cliente, enfim, a todo esse conjunto de ações que fazem parte da rotina da empresa. (OSTERWALDER e PIGNEUR, 2011). 
"Parcerias Principais" dizem respeito aos colaboradores externos, que realizam as funções terceirizadas da instituição, bem como, alguns recursos humanos, e também materiais, que são desenvolvidos por pessoas de fora da empresa, um exemplo bem comum, são as empresas de contabilidade, que compreendem os profissionais contratados externamente. (OSTERWALDER e PIGNEUR, 2011).

A "Estrutura de Custo" é o elemento que resulta do plano de negócios, desenvolvido por meio de uma gestão de projetos de qualidade, que traçam as principais atividades, objetivos, metas, missão, visão e valores, que são inerentes à atividade da organização. (OSTERWALDER e PIGNEUR, 2011).

Assim, o modelo aqui apresentado, possui elementos essenciais do plano de negócios que, pode ser perfeitamente aplicado e bem desenvolvido no ramo de fontes de energia renováveis, mais especificamente na área de energia solar e, ainda pode-se valer de um desenvolvimento de projetos adequado a seus produtos/serviços, a fim de facilitar a compreensão, e permitir participações mais ativas, por parte dos colaboradores, e demais profissionais que, direta ou indiretamente encontram-se inseridos na empresa.

\subsection{DESENVOLVIMENTO DE PROJETOS}

A administração de um produto ou serviço, necessita de um projeto básico que, sumariamente consiste em planejar e administrar "empreendimentos que fazem parte, consciente ou inconscientemente, do dia a dia de qualquer organização. A visão da empresa influenciará sensivelmente no sucesso dos projetos." (SILVA, 2012, p. 14).

O PMBOK é um instrumento fundamental da área de gestão de negócios, nele são encontrados os elementos primordiais de toda a gerência dos projetos de uma organização, em quaisquer áreas que se pretende realizar algum tipo de planejamento. Ele estabelece um conjunto de conhecimentos, que devem estar presentes em um gerenciamento de negócios adequado.

Logo, o gerenciamento de projetos ocorre de maneira bem específica, quando se fala no âmbito de desenvolvimento de engenharias sustentáveis, principalmente devido ao fato de essa área necessitar de uma atualização mais constante, e com 
uma frequência que favoreça 0 desenvolvimento de novas técnicas de administração.

Isso se deve ao fato de, prioritariamente os elementos que constituem a sustentabilidade serem aqueles que exigem, cada vez mais empenho por parte de seus colaboradores, no sentido de que os clientes anseiam por inovações e, portanto, não aceitam que the sejam oferecidos produtos e/ou serviços que sejam incompatíveis com as suas reais necessidades.

Logo, também é fundamental que todas as fases do negócio se articulem de maneira bem estruturada, conforme se pode perceber a seguir:

Figura 7- A Relação Entre as Fases do Processo de um Projeto

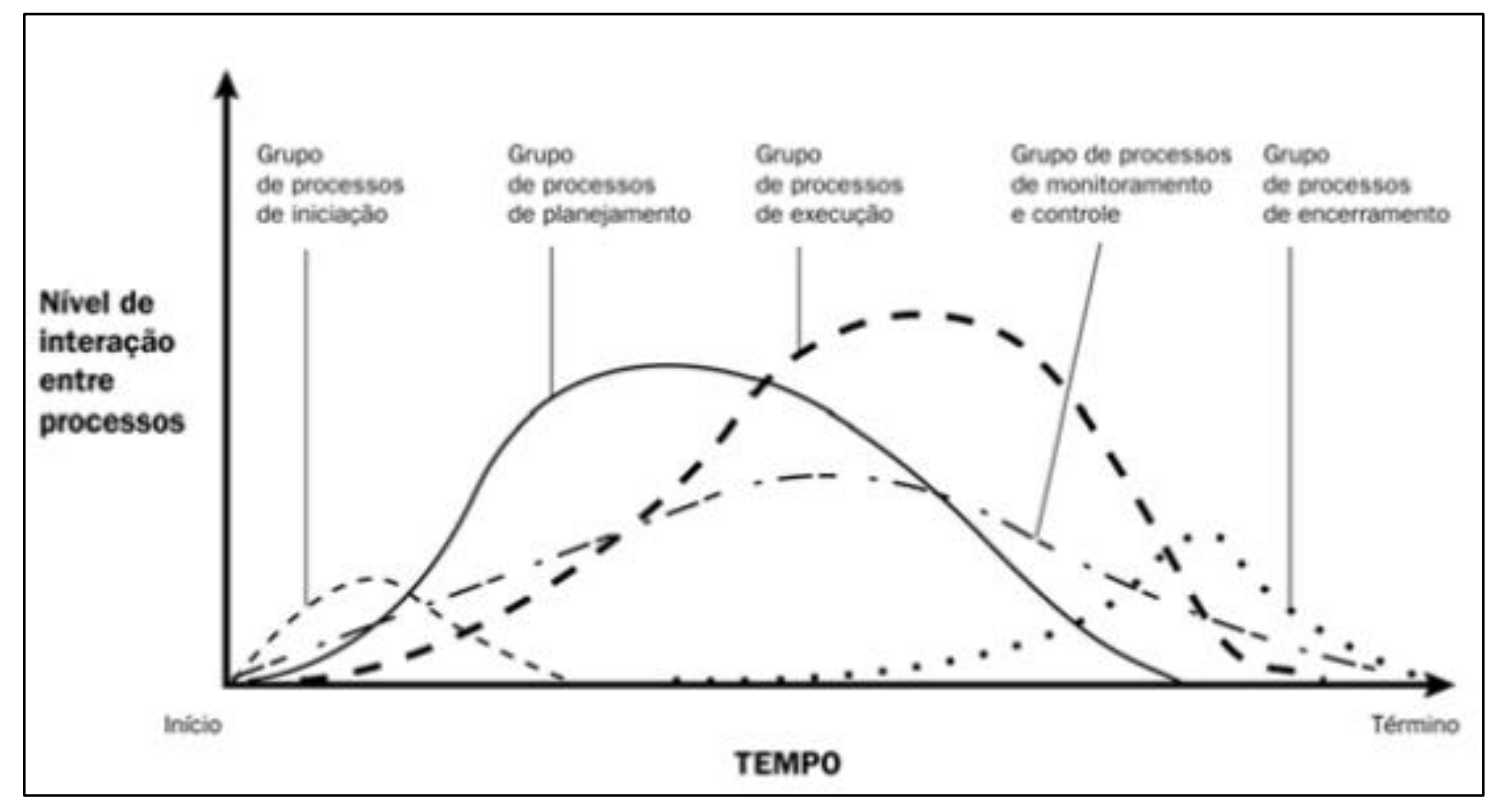

Sendo assim, quando se fala em gestão de projetos é preciso que exista uma estrutura adequada de atualizações, ou seja, que o projeto vislumbre o comportamento do mercado, como sendo algo que não apenas vise o aumento de vendas, mas também que tenha a intenção de oferecer um produto de qualidade, por meio de um serviço de atendimento, que seja devidamente capacitado, e qualificado, para saber lidar com o público para o qual são direcionados tais serviços. Assim, como bem estabelece Vargas (2003):

A gestão de projetos proporciona inúmeras vantagens sobre as demais formas de gerenciamento, tendo se mostrado eficaz em alcançar resultados desejados, dentro do prazo e orçamento definidos pela organização. Sua principal vantagem está na aplicabilidade a projetos de qualquer porte, 
independente de seu tamanho, complexidade e necessidade e restrições de recursos. (VARGAS, 2003, apud CAMPOS, 2012, p. 2).

Nesse sentido, a gestão de projetos, em âmbito sustentável deve abranger todos os processos, incluindo desde o início até a concretização do mesmo, ou seja, desde a sua elaboração no plano das ideias, até a sua conclusão, na prática. De forma que sejam considerados os elementos primordiais de sua execução, além de elencar possíveis vícios futuros, antecipando a resolução dos mesmos, a fim de ter um mecanismo de resposta mais dinâmico, e rápido o que, por sua vez, favorece, e muito a solução de problemas, além de tornar o trabalho mais eficaz e eficiente.

Conceituar um projeto pode ser uma tarefa complicada, primordialmente devido ao fato dela abrir um leque de opções, que podem tornar confusa a compreensão do assunto que se pretende abordar, de acordo com Silva (2012):

\begin{abstract}
A palavra "projeto" costuma causar algumas confusões semânticas, já que pode ser interpretada de diferentes formas, dependendo da área de conhecimento. Por exemplo, é comum ver profissionais de construção civil associando a palavra "projeto" ao trabalho inicial de uma obra, desenvolvido pelo arquiteto, e utilizando o termo "obra" para designar o restante do empreendimento. Já na área de desenvolvimento de produtos da manufatura tradicional, alguns profissionais designam "projeto" como o desenho feito em uma ferramenta de CAD. (SILVA, 2012, p. 15).
\end{abstract}

Entretanto, no presente estudo, o conceito de um projeto compreende, em regra geral, um elemento que norteia todos os trabalhos de uma organização, ou seja, é nele que estão presentes os objetivos, metas, hipóteses, enfim, todos esses conteúdos que visualizam o cumprimento da função de algo, que pode ser uma empresa, um programa, uma máquina, enfim, para que se alcance o sucesso, e se possa cumprir com o seu papel é preciso que exista esse planejamento.

Existem diversos autores que conceituam o projeto, como Maximiano (2002, apud CHICARINO, 2005, p. 14), por exemplo, que compreende que um projeto pode ser definido como sendo um "empreendimento temporário ou uma sequência de atividades com começo, meio e fins programados, que tem por objetivo fornecer um produto singular, dentro de restrições orçamentárias.".

Nesse sentido, todos os conceitos apresentam uma série de componentes de suma relevância para a temática, que devem ser destacados, e reconhecidos como elementos que auxiliam na execução de todas as etapas, desde o escopo, até a necessidade de recursos, sejam eles humanos, orçamentários, materiais ou financeiros, planejamento, qualidade, prazos, enfim, todos que encontram-se no 
desenvolvimento do projeto, e que se constituem como sendo essenciais, para que os seus sucessos sejam alcançados de maneira plena. (CHICARINO, 2005).

Os principais aspectos a serem observados em uma gestão de projetos devem ser compatíveis com as necessidades da organização ou do que se pretende planejar, no sentido de que sejam considerados, e contemplados todos os aspectos dessas perspectivas, de maneira que não apenas a empresa seja contemplada, por meio do plano, mas sim todos os demais indivíduos que se encontram, direta ou indiretamente, em contato com o seu desenvolvimento e que, de alguma maneira, sofrem influências do sucesso do projeto.

\subsubsection{GERENCIAMENTO DO ESCOPO DO PROJETO}

O gerenciamento do escopo de um projeto deve considerar aspectos imprescindíveis para que se garanta o máximo de informações a respeito do planejamento final, considerando que o escopo é o que, de fato, conduz os demais processos da organização, como se pode perceber pela afirmação da Escola Nacional de Administração Pública (2014):

Escopo do Projeto são as necessidades das partes interessadas que
devem ser atendidas ao final do projeto. O Escopo do Projeto contempla
tudo que deve ser atendido para o sucesso do projeto. O gerenciamento do
escopo do projeto inclui os processos necessários para assegurar que o
projeto inclui todo o trabalho necessário, e apenas o necessário, para
terminar o projeto com sucesso. O gerenciamento do escopo do projeto está
relacionado principalmente com a definição e controle do que está e do que
não está incluso no projeto. (ENAP, 2014, p. 6).

O escopo de um projeto físico é um dos elementos primordiais de todo e qualquer planejamento de ação, uma vez que a construção do mesmo é o que vai definir as bases para a elaboração de um objeto definitivo e acabado, em sua mais completa perfeição, ou seja, tudo que é necessário para que um projeto seja concluído, com sucesso, são definidos na elaboração dessa ferramenta que há muito é utilizada na administração, seja ela qual for desde a fabricação de painéis solares, até a distribuição de kits fotovoltaicos.

Dentre os processos de criação do escopo é essencial ter em mente uma linha de raciocínio a ser seguido que oriente as práticas futuras, desta maneira, o planejamento está inserido no projeto desde o risco de seu escopo e não apenas é o resultado final e já acabado sendo, assim, resultado de uma série de processos, 
dentre os quais podemos destacar: gerenciamento do escopo, lista de condicionalidades e viabilidade, elaboração do plano, monitoramento do projeto e sua evolução. (ENAP, 2014).

Assim, os processos são de suma importância para que o escopo se estabeleça de forma bem apresentável e, com isso, que consiga se considerar um serviço de boa qualidade e que valorize os seus criadores.

As características do escopo são bem semelhantes aos seus processos, no entanto, o processo é muito preso a um sistema de regularização, ao passo em que a característica vai vir de encontro a necessidades dos consumidores e, também dos demais envolvidos no processo.

Os componentes de um plano de gerenciamento do escopo incluem:

- O processo da especificação detalhada do escopo do projeto.

- O processo que especifica como será obtida a aceitação formal das entregas do projeto concluídas.

- O processo para controlar como as solicitações de mudança na especificação do escopo do projeto detalhada serão processadas. Este processo está diretamente ligado ao processo Executar o Controle Integrado de Mudanças. (ENAP, 2014, p. 7).

Pode-se dizer, no entanto, de uma maneira mais ampla e generalizada, que um escopo deve ser caracterizado a partir de um planejamento, que, por sua vez, deve seguir um cronograma bem estruturado e, também de forma que atenda às necessidades e anseios do seu público que, gradativamente tem se tornado cada vez mais exigente e capaz de escolher, com detalhes, qual a melhor ferramenta que o atende. Em seguida é imprescindível, também uma apresentação prévia do escopo, para que sejam realizadas transformações e melhorias adequadas e, por fim, mas não menos importante, sempre se deve considerar as atualizações, não apenas de mercado, mas também de mudanças sociais e de hábitos dos indivíduos, uma vez que os padrões tecnológicos têm sofrido metamorfoses a uma velocidade incrível e que vai diretamente de encontro com as exigências do público vigente. (ENAP, 2014).

Desta maneira, pode-se dizer que mais do que exercer um controle rígido sobre o processo, que também é importante devido às particularidades e urgências em se atualizar, mas também é preciso haver flexibilidade para que mudanças sejam realizadas ao longo da execução para que se aprimorem os projetos.

Portanto, não apenas a comunicação corporativa é essencial para as instituições responsáveis pela distribuição das mercadorias ofertadas, mas também 
é fundamental que os gerentes, designers, técnicos, engenheiros, enfim, todos que formam equipes, que lidam com as mais diversas maneiras de administração, necessitam caminhar considerando os objetivos, metas e missões que the foram traçadas no escopo, a fim de revelar o total comprometimento com o produto e, principalmente, com que o mesmo atenda aos seus consumidores.

\subsection{ANÁLISE DE RISCO/SWOT}

Os projetos sejam eles quais forem, ou seja, em qualquer ramo empresarial que se encontrem, apresentam riscos, até mesmo nas menores atividades que não exigem certo grau de complexidade, mesmo ali existem riscos que podem comprometer todo o projeto. (COSO, 2007).

Sendo assim, é fundamental que todos os riscos sejam devidamente calculados para que não surjam eventualidades pelo caminho e, desta forma, seja possível contornar a situação caso algo não esperado ocorra durante a execução do projeto, o que deve ser vislumbrado desde o planejamento, até a realização do escopo, definição do cronograma, ou seja, em todos os passos do projeto, os riscos devem ser considerados e, assim, ser passíveis de adequações e correções que venham de encontro às necessidades do projeto e de todos os elementos que o circundam, garantindo a qualidade ao final da execução. (ENAP, 2014).

\footnotetext{
O gerenciamento de riscos tem o objetivo de tentar identificar todos os riscos possíveis, maximizar os resultados dos eventos positivos, minimizar seus impactos e consequências, gerenciar as responsabilidades de materialização dos eventos, e prover planos contingenciais para suprir os riscos que eventualmente se materializem. (NASCIMENTO, 2003, p. 11).
}

O gerenciamento de riscos deve obedecer a uma série de programações, tais como: identificação e análise de riscos que, por sua vez, agindo em conjunto trazem diversos benefícios para a instituição de maneira que exista um equilíbrio e se definam metas para solucionar possíveis problemas, considerando-se que quanto mais se conhecem os contratempos, mais fácil fica de lidar com os mesmos e solucioná-los de maneira positiva. 
A identificação dos riscos, basicamente consiste em listar quais as possíveis ameaças ao cumprimento do projeto e, de que maneira tais elementos podem vir a causar impactos negativos para seu processo de elaboração.

\begin{abstract}
Ocorrências de risco constituem os efeitos potenciais adversos ao projeto. A sua identificação deve ser feita, primeiramente, durante a iniciação do projeto, e, em seguida, no seu planejamento. Durante o início do projeto, o líder deve identificar as interfaces do projeto e o grau de dificuldade em alcançá-las. Também pode haver logo uma identificação dos riscos internos, sendo estes previstos com uso de nova tecnologia ou nova força de trabalho. (NASCIMENTO, 2003, p. 16).
\end{abstract}

Tais ameaças podem ser detectadas a partir do vislumbre que o gestor tem do projeto, de uma maneira tanto geral quanto específica, no intuito de identificar esses riscos é essencial que sejam esmiuçados os detalhes inerentes à análise dos objetivos, verificação do feedback, revisão do cronograma, acompanhamento do fluxograma e o levantamento de hipóteses possíveis para, caso surjam imprevistos, as soluções transcorram plenamente.

A partir do momento em que se realiza uma análise dos objetivos é possível perceber quais são passíveis de serem alcançados, bem como, quais os que podem acarretar problemas futuros para a instituição que está realizando o projeto, de maneira que tais metas sejam passíveis de sofrer adaptações ao longo da execução, considerando-se as intervenções, tanto internas quanto externas, que podem ocorrer. (NASCIMENTO, 2003).

A revisão do cronograma, por sua vez, é fundamental para que as metas sejam cumpridas em tempo hábil e possam, assim, fazer com que a apresentação agrade a todos os interessados, de forma que o produto ou serviço seja oferecido, com qualidade, e dentro de um prazo pré-determinado, mas também, nesse cenário é possível reconhecer riscos ou problemas possíveis que, por meio dos atrasos, podem ser identificados e contornados para que os riscos sejam minimizados e os possíveis problemas solucionados. (NASCIMENTO, 2003).

É necessário identificar as falhas do cronograma na medida em que se executa o planejamento. O cronograma deve contar com recursos designados e disponíveis para a realização do trabalho, pois a falta de pessoal qualificado para exercer as funções representa um risco. A entrega do produto sempre está sujeita à avaliação para a viabilização do término do trabalho. Pode-se dizer que também os marcos são objetos de avaliação com vistas à viabilidade. (NASCIMENTO, 2003, p. 16). 
O acompanhamento do fluxograma, por sua vez, demonstra claramente se todos os passos estão sendo seguidos e se estão sendo respeitados os passo a passo determinados anteriormente que trazem uma série de benefícios para a execução do projeto, bem como, para que um escopo bem apresentado seja bem aceito pelos clientes e, assim, o cumprimento de metas aliado com a execução plena e bem programada origine um trabalho que, de fato, demonstre compromisso com o cliente, o produto e, ainda, com os profissionais que nele tem trabalhado durante todo o período de realização do projeto.

Por último, mas não menos importante, para que uma identificação de riscos de fato surja efeitos benéficos para o projeto é fundamental o levantamento de hipóteses, antes de qualquer decisão a ser tomada efetivamente, é fundamental que se reconheçam as possíveis soluções para problemas ou conflitos para que, assim, caso venham a ocorrer, já existam mecanismos que solucionem os imprevistos, reduzindo o tempo gasto com discussões e debates e acarretando mais objetividade da elaboração e, consequentemente, também agilidade na execução do trabalho. (NASCIMENTO, 2003).

\footnotetext{
$\mathrm{Na}$ fase de identificação dos riscos devemos somente nos preocupar em enumerar os riscos, relacionar suas causas e os efeitos para o projeto. A análise e avaliação já fará parte do próximo passo no processo de gerenciamento. (NASCIMENTO, 2003, p. 16).
}

Desta maneira, a identificação de risco não consiste na mera espera pelo feedback para que se contornem os problemas, mas também deve englobar outros aspectos que são igualmente importantes para que os profissionais saibam como agir diante das adversidades e compreendam que quanto mais bem preparados estiverem para agir perante tais situações, mais rapidamente e, com qualidade, os problemas serão solucionados e, assim, os riscos poderão ser reduzidos.

$\mathrm{Na}$ intenção de identificar os riscos do projeto, mais do que saber quais as maneiras de se agir, é elementar que existam os instrumentos adequados para a verificação dos riscos, de maneira que a detecção se torne mais dinâmica e rápida para que, assim, seja possível a verificação mais hábil e se otimize o tempo de contornos de possíveis problemas para que a execução do projeto, bem como os seus prazos, não sejam comprometidos. 
De fato existem diversas ferramentas que podem auxiliar o gestor e seus colaboradores, tais como, entrevistas com a equipe; listas de verificação e formulários de informação de risco. (NASCIMENTO, 2003).

Porém, existe um elemento essencial, que auxilia na identificação dos riscos, principalmente quando se fala em um plano de negócios de uma empresa que agrega valores sustentáveis e também tecnológicos, como é o caso da venda de kits fotovoltaicos que são utilizados na produção de energia solar e, consequentemente, também atuam diretamente sobre o desenvolvimento de usinas solares. Assim, a matriz SWOT (Strenght Weakness Opportunities Threats), por sua vez, visa a identificação de forças, fraquezas, oportunidades e ameaças que influem, direta ou indiretamente, sobre o plano de negócios da organização.

\begin{abstract}
A Análise SWOT é considerada uma ferramenta clássica da administração. Não há executivo de grande empresa que não a conheça. (...) A Análise SWOT pode ser usada de diversas formas, mas o empreendedor pode empregá-la como uma ferramenta de autoconhecimento, análise contextual e guia para a definição de um plano de ação. SWOT é uma sigla em inglês dos termos Strengths (pontos fortes), Weaknesses (pontos fracos), Opportunities (oportunidades para o seu negócio) e Threats (ameaças para o seu negócio). Os pontos fortes e fracos, em geral, estão dentro da própria empresa, enquanto as oportunidades e as ameaças, na maioria dos casos, têm origem externa. (NAKAWAGA, 2011, p. 1).
\end{abstract}

A imagem apresentada a seguir estabelece de forma bem clara e objetiva de que forma a matriz SWOT pode ser preenchida, afim de auxiliar no processo de tomada de decisões da empresa, haja vista que faz uma análise de quatro pontos essenciais, tanto internos quanto externos, que oferecem risco e benefícios para a organização.

Figura 8-Análise SWOT

\title{
Forças
}

Fraquezas

- Produto com alta durabilidade, baixo custo de manutenção e garantia de 25 anos

- A empresa contará com funcionário para a regularizar o sistema junto a concessionária

- Prazo de instalação de projetos
- Falta de estoque

- Tecnologias ainda em desenvolvimento

- Empresa de pequeno porte que carece de estrutura 


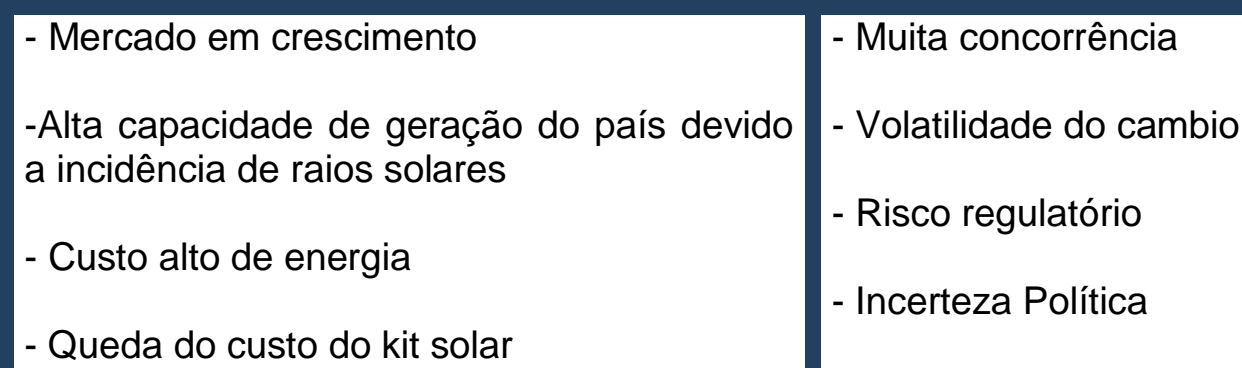

Logo, após o preenchimento da matriz SWOT é fundamental que os pontos fracos e fortes sejam analisados, afim de que sejam oportunizadas melhorias na organização, de modo que o seu plano de negócios alcance resultados satisfatórios, eficientes e eficazes.

Sendo assim, a análise dos riscos, geralmente realizada a partir dos dados colhidos pela análise SWOT, é uma avaliação prévia de como proceder diante do acontecimento efetivo da situação problema, ou seja, aqui os riscos podem e devem ser catalogados e inseridos em um determinado grau de relevância para que, assim, seja pos

Fonte: Do autor seguir uma ordem de prioridade que cause menos impactos ao trabalho. (NASCIMENTO, 2003).

Para que exista uma maior compreensão sobre os riscos aos quais o trabalho estará exposto é fundamental que se definam graus de risco tais como: alto, moderado e baixo, no intuito de se estabelecer quais serão os mais urgentes de serem solucionados.

Juntamente com a identificação dos riscos, devemos identificar os
acionadores que mostrarão se o risco já ocorreu ou está prestes a ocorrer.
Esta identificação é feita através de conversas com as pessoas envolvidas
no projeto que mais serão afetadas pelo evento dos riscos e até mesmo
com as pessoas que sentirão seus impactos. O ideal é questionar como
elas ficariam cientes da ocorrência do evento e como poderiam prever o
evento antes da sua ocorrência. Para cada risco abordado, devemos criar
uma lista de observação que mostre os possíveis acionadores, a
probabilidade de sua ocorrência e quem deve observar o acionador.
(NASCIMENTO, 2003, p. 24).

A partir do momento em que se definem quais são as prioridades fica mais viável a solução dos impasses e, assim, as análises de risco terão um significado mais específico, trazendo uma série de benefícios para o projeto, tais como: redução 
de erros, agilidade na intervenção, feedback mais positivo, dentre outros. (COSO, 2007).

\begin{abstract}
Antes de desenvolver as respostas a todos os riscos, o gerente deve se preocupar em identificar e analisar somente os riscos com alta e média prioridade. Alguns riscos são de baixa prioridade de acontecimentos, e não se deve perder tempo com eles. (NASCIMENTO, 2003, p. 55).
\end{abstract}

Nesse sentido, torna-se essencial que existam mecanismos de resposta frente aos riscos, ou seja, maneiras de se ter soluções práticas e que venham de encontro às reais necessidades do trabalho, tornando, desta maneira, o seu desenvolvimento de forma mais clara e objetiva.

\title{
3.3 MARKETING
}

O Marketing é considerado uma área de imenso destaque em todos os mercados financeiros e também nos mais diversos ramos empresariais, devido ao fato de ser um elemento que traz benefícios a curto, médio e longo prazos para a empresa, considerando-se que o seu papel é fundamentalmente trazer o cliente par a instituição, demonstrando, por meio de uma série de ferramentas o quão bom é o seu produto e/ou serviço para a vida daquele indivíduo e de que maneira ele pode utilizar-se de seus instrumentos para promover o seu bem estar e dos demais que se encontram em seu entorno.

Nesse sentido as configurações de cada empresa é que vai determinar qual a melhor maneira de se utilizar o marketing em seu potencial mais exploratório, uma vez que o mesmo é de grande relevância para o desenvolvimento das atividades da organização.

(...) O marketing é dirigido para satisfazer necessidades e desejos humanos e, dessa forma, precisa levar em consideração o público alvo antes de tudo, conhecendo-o para poder satisfazê-lo. Isso já coloca o público-alvo no centro de qualquer ação de marketing, e conhecê-lo é condição sine qua non para estratégias de sucesso. Se o comportamento do público-alvo muda, as estratégias de marketing também precisam mudar. (GABRIEL, 2010, p. 28).

O marketing deve ser bem definido no pensamento dos dirigentes da corporação e não apenas ser realizado tendo por base a mera propaganda e publicidade para atrair o público, mas deve ser pensado de forma bem elaborada 
para que possa realmente passar o que de fato a empresa representa para os seus clientes.

Assim sendo é de suma importância que, mais do que a proposta de preço $x$ produto (que também possui sua significância) se utilize um canal de comunicação que seja voltado para atender as necessidades do seu público-alvo e, assim se firmar de maneira plena no mercado de atuação.

\begin{abstract}
Dessa forma, como o marketing se baseia na troca, e a troca por natureza é um processo em que ambas as partes atuam livremente, por vontade própria, e acham adequado fazê-la, o marketing envolve transações em que, teoricamente, as partes envolvidas sempre saem ganhando. Por isso, quanto mais o marketing entende o seu público-alvo e as transformações em seus hábitos, necessidades e desejos, maior é a probabilidade de saber o que pode ser oferecido a esse público, que o interesse, para que ocorra a troca. (GABRIEL, 2010, p. 29).
\end{abstract}

Os diversos tipos de abordagens do marketing, por assim dizer, necessitam levar em conta que existe um grupo de consumidores cada vez mais exigente e ansioso por mercadorias que o satisfaçam não no que se refere apenas ao valor comercial, mas também ao que se oferece para além do menor preço. Desta maneira é essencial que se considere um conjunto de coisas para se realizar atividades de marketing de forma bem estruturada, tais como: Oferta de Valor; Qualidade no Produto; Canais de Comunicação e Relacionamento com o Cliente.

A SunFor trabalhará com duas frentes para desenvolver o marketing. A primeira, muito comum nos dias atuais que é o marketing nas redes sociais, esse tipo de propaganda é muito útil pois é barata, alcança um número enorme de clientes e é possível chegar ao público-alvo a partir da boa utilização dos dados. É possível fazer a divulgação do dia a dia da empresa, divulgação dos projetos, direcionamento da publicidade e também possibilita o cliente a ter um contato direto com a empresa, facilitando a comunicação. A segunda frente de marketing será através do apoio com recursos financeiros para ações sociais de sustentabilidade e voltadas ao meio ambiente. Essas ações reúnem um público com grandes influências de comportamento autossustentável que estão diretamente ligada a atividade da empresa. 


\subsection{PLANEJAMENTO FINANCEIRO}

A administração de finanças é um ramo da gerência que consiste em trabalhar com os elementos da economia de uma empresa, ou seja, planejar, organizar e orientar a aplicação de valores, visando à estabilização das receitas e expansão dos lucros.

O planejamento financeiro, nesse sentido, para se fazer cumprir com os seu papel dentro de uma organização empresarial, precisa atentar-se para três questões essenciais: Orçamento de Capital; Estrutura de Capital; Administração do Capital de Giro, que são os elementos responsáveis pelo processo de tomada de decisões do administrador de finanças.

[...] A primeira questão diz respeito aos investimentos em longo prazo da empresa. $O$ processo de planejamento e gerência dos investimentos em longo prazo da empresa é denominado orçamento de capital. Nessa função, o administrador financeiro procura identificar oportunidades de investimento que possuem valor superior a seu custo de aquisição. Em termos gerais, isso significa que o valor dos fluxos de caixa gerados pelo ativo excede o custo de tal ativo [...]. (ROSS, 2000, p. 39).

Assim, atentando-se para esse elemento inicial, a administração financeira cumpre com um papel fundamental para a instituição corporativa: manter os lucros e, com isso, evitar problemas de investimentos e demais erros que poderiam surgir a partir da queda da receita.

[...] A segunda questão para o administrador financeiro diz respeito a como a empresa obtém os financiamentos necessários para sustentar os investimentos em longo prazo. A estrutura de capital (ou estrutura financeira) refere-se à combinação específica entre capital de terceiros em longo prazo e capital próprio que a empresa utiliza para financiar suas operações [...]. (ROSS, 2000, p. 39).

Tal elemento é fundamental para financiar as atividades da organização, de modo que a operacionalização de suas funcionalidades transcorra a partir da configuração mais eficiente, e eficaz possível.

Logo, para se instalar e estruturar o capital de maneira consciente ocorre que as receitas da empresa devem se articular com o investimento de terceiros e, assim, alcançar as metas pré-estabelecidas no intuito de gerenciar adequadamente os gastos, e elevar a lucratividade de forma responsável. 
[...] A terceira questão diz respeito à administração do capital de giro. A expressão capital de giro refere-se aos ativos em curto prazo da empresa, tais como estoques, e aos passivos em curto prazo, tais como pagamentos devidos a fornecedores. A administração do capital de giro da empresa é uma atividade cotidiana que assegura que os recursos sejam suficientes para continuar a operação, visando evitar interrupções dispendiosas. Isso envolve diversas atividades relacionadas aos recebimentos e desembolsos da empresa [...]. (ROSS, 2000, p. 40).

Logo, pode-se dizer que, a administração do capital de giro engloba o orçamento e a estrutura do capital, de maneira que gerencia ambos os elementos, fornecendo o equilíbrio necessário às finanças o que, por sua vez, contribui para que os objetivos da gestão financeira sejam plenamente alcançados.

A gestão financeira necessita atender a alguns requisitos básicos para poder cumprir com a sua meta principal, que seria basicamente ampliar a possibilidade de lucratividade da instituição empresarial à qual a mesma atende.

Deste modo, existem alguns objetivos essenciais, que devem ser cumpridos pela gestão financeira, para que alcance a lucratividade, de maneira que a gestão das receitas da organização se dê de maneira plena e satisfatória, sempre tendo em vistas a missão da empresa como norteadora do desenvolvimento de suas atividades, a saber: Valorizar os acionistas; Elevar o valor das ações de mercado; Ampliar as riquezas da organização. (ROSS, 2000).

- Valorizar os acionistas - Os acionistas são essenciais para o processo de tomada de decisões em uma gestão financeira, por isso é fundamental que os mesmos sintam-se valorizados ao longo de toda a tramitação administrativa do gestor financeiro, considerando que são eles que têm o poder do voto, e decidem, de fato, a aprovação de determinadas medidas propostas. Assim, a administração financeira "age de acordo com o melhor interesse dos acionistas ao tomarem decisões que aumentam o valor das ações da empresa." (ROSS, 2000, p. 43).

- Elevar o valor das ações de mercado - O mercado, independentemente da área na qual a empresa encontra-se inserida, torna-se gradativamente mais competitivo e, por isso, existe um caráter de emergência no objetivo de valorizar o produto, tendo em vista um retorno mínimo e também a satisfação dos grupos interessados pelos produtos ou serviços ofertados. Logo, "o objetivo de maximizar o valor das ações evita problemas associados aos diferentes objetivos, não existe ambiguidade nesse critério, e não há questões sobre curtos ou longos prazos." (ROSS, 2000, p. 43). 
- Ampliar as riquezas da organização - Cabe ressaltar que a ampliação das riquezas de uma organização é um objetivo fundamental no processo de administração financeira, e pode-se afirmar que a mesma é resultado de um conjunto de elementos que, desde que bem planejados, tornam a empresa mais valorizada, bem quista no mercado e pelos grupos de interesse.

[...] Maximização de lucros talvez seja o objetivo empresarial mais frequentemente citado, mas não é um objetivo muito preciso. Estamos falando do ano em curso? Se for isso atitudes como postergar manutenção, a não-reposição de estoques e outras medidas de corte de custos a curto prazo tenderão a aumentar o lucro agora, mas essas atitudes não são necessariamente desejáveis. O objetivo de maximizar os lucros pode referirse a algum tio de lucro em longo prazo ou médio, mas não é claro o sentido exato disso. Indo direto ao assumo, esse objetivo não nos diz qual é o equilíbrio adequado entre lucros correntes e lucros futuros [...]. (ROSS, 2000, p. 43).

Sendo assim, para que exista um cumprimento efetivo dos objetivos da administração financeira é necessário que o gestor esteja a par do cenário atual do capitalismo, na sociedade à qual a organização encontra-se inserida, além de reconhecer minuciosamente o mercado, estar em harmonia com o cenário financeiro da atualidade, haja vista que tais investigações são essenciais para o trabalho com finanças.

\subsubsection{INVESTIMENTO INICIAL}

A SunFor será uma empresa de pequeno porte, onde o capital inicial será obtido por recursos individuais do empresário, o sistema de tributação sobre células fotovoltaicas em módulos caem sobre o NCM 854140. Os investimentos iniciais para constituição da empresa e início de operação estão descritos nas tabelas a seguir, primeiramente o investimento pré-operacional em capital de giro, legalização, criação do site, e treinamento dos funcionários:

\begin{tabular}{|c|c|c|}
\hline Invst. Pré Operacional em Capital de Giro & & \\
\hline Legalização Empresa & $\mathrm{R} \$$ & $2.200,00$ \\
\hline Logomarca & $\mathrm{R} \$$ & $1.380,00$ \\
\hline Site & $\mathrm{R} \$$ & $1.100,00$ \\
\hline Capital funcional para os 6 primeiros meses & $\mathrm{R} \$$ & $156.000,00$ \\
\hline
\end{tabular}




\begin{tabular}{|l|l|lc|} 
& $\mathrm{R} \$$ & $4.500,00$ \\
\hline Treinamento ${ }^{* * * *}$ & & \\
\hline SUB-TOTAL & $\mathrm{R} \$$ & $165.180,00$ \\
\hline
\end{tabular}

$\mathrm{Na}$ tabela a seguir, os investimentos

para a operação:

\begin{tabular}{|c|c|c|}
\hline Invst. fixo na operação & & \\
\hline Ferramentas montagem dos painéis * & $\mathrm{R} \$$ & $1.800,00$ \\
\hline Ferramentas de elétrica e manutenção** & $\mathrm{R} \$$ & 500,00 \\
\hline Uniformes & $\mathrm{R} \$$ & 700,00 \\
\hline EPI Trabalho em Altura & $\mathrm{R} \$$ & $2.500,00$ \\
\hline Infraestrutura *** & $\mathrm{R} \$$ & $6.600,00$ \\
\hline SUB-TOTAL & $\mathrm{R} \$$ & $12.100,00$ \\
\hline
\end{tabular}

$\left(^{*}\right)$ - Ferramentas Diversas e escada

$\left.{ }^{* *}\right)$ - Multímetro, teste de voltagem

$\left(^{* * *}\right)$ - Computador e Software

$\left.{ }^{* * * *}\right)$ - Curso e treinamento

Dessa forma o investimento inicial total será de $R \$ 177.280,00$ como descrito na tabela a seguir:

\begin{tabular}{|c|c|cc|}
\hline Invst. Pré Operacional em Capital de Giro & $R \$$ & $165.180,00$ \\
\hline Invst. fixo na operação & $\mathrm{R} \$$ & $12.100,00$ \\
\hline TOTAL & $\mathrm{R} \$$ & $177.280,00$ \\
\hline
\end{tabular}


Não haverá investimento em estoque inicial pois não será mantido estoque de pronta entrega e os pedidos serão feitos de acordo com a demanda. Nos dias atuais, empresas do ramo de geração fotovoltaica centralizada já possuem grande estoque disponível dentro do território nacional e parecerias com essas empresas serão essenciais em caso de pico de demanda.

\subsubsection{FUNCIONÁRIOS E REMUNERAÇÃO}

A SunFor contará com o sócio atuando na área financeira e mais cinco funcionários, um na área comercial atuando também no suporte para regularização do sistema junto a distribuidora de energia, um estagiário na área administrativa, um engenheiro eletricista que será o responsável pelo projeto e atuará coordenando a equipe de montagem, e dois auxiliares de montagem que serão responsáveis pela instalação e montagem do sistema. Todos receberão salários fixos mais benefícios de vale transporte e vale alimentação como descrito na tabela a seguir:

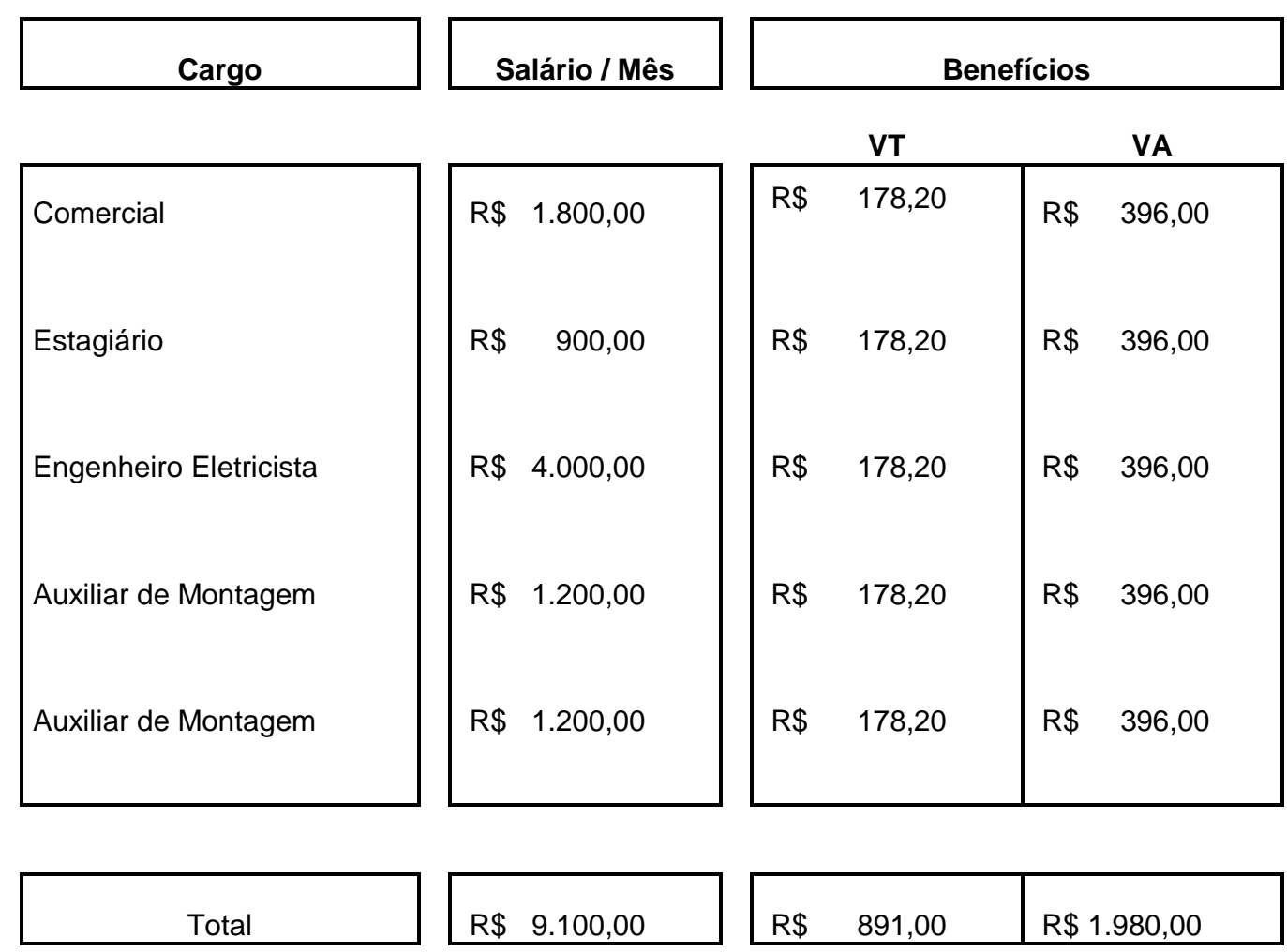




\subsubsection{PREÇOS E RECEITAS ESTIMADAS}

Os preços praticados pela SunFor são similares aos da concorrência e a margem de cada produto se dará pelo tamanho do projeto, onde, os projetos grandes terão maiores margens e os projetos pequenos terão margens menores. Há uma explicação para essa política de preços pois os projetos maiores envolvem mais tempo de trabalho e mais risco de instalação devido ao peso e quantidade de equipamento em cima dos telhados, portanto, deverão dar mais retorno. $\mathrm{Na}$ tabela abaixo estão descritos os produtos, os respectivos custos e preços, e prazos de instalação. É importante ressaltar que esses valores contemplam o produto final de venda ao cliente, onde estão inclusos todos os componentes que formam o "kit fotovoltaico" (módulos, inversores, cabos, e estrutura de fixação).

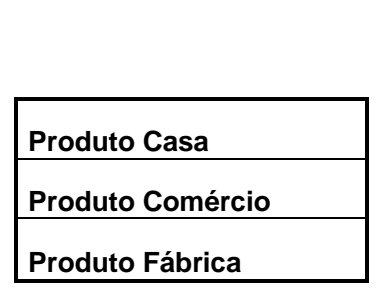

\begin{tabular}{|lr|}
\hline \multicolumn{2}{|c|}{ Custo } \\
\hline$R \$$ & $31.000,00$ \\
\hline$R \$$ & $215.000,00$ \\
\hline$R \$$ & $432.000,00$ \\
\hline
\end{tabular}

\begin{tabular}{|r|}
\hline \multicolumn{1}{c|}{ Margem } \\
\hline $77,42 \%$ \\
\hline $80,93 \%$ \\
\hline $83,10 \%$ \\
\hline
\end{tabular}

\begin{tabular}{|lr|}
\hline \multicolumn{2}{|c|}{ Preço } \\
\hline$R \$$ & $55.000,00$ \\
\hline$R \$$ & $389.000,00$ \\
\hline$R \$$ & $791.000,00$ \\
\hline
\end{tabular}

\begin{tabular}{|c|}
\hline Prazo de instalação (em dias) \\
\hline 2 \\
\hline 8 \\
12 \\
\hline
\end{tabular}

A capacidade de produção da empresa dá pelo prazo de instalação multiplicado pela quantidade de projetos referentes a cada produto. Considerando a média de 20 dias úteis por mês a capacidade será:

\begin{tabular}{|l|}
\hline Produto \\
Casa
\end{tabular}
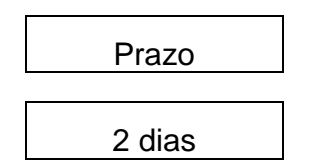

Capacidade de instalação

10 sistemas por mês 
ou

Comércio

\begin{tabular}{|c|}
\hline 8 dias \\
\hline ou \\
\hline 12 dias \\
\hline
\end{tabular}

A partir dessas premissas, foi traçado o cenário otimista de desempenho da SunFor para os primeiros anos de funcionamento da empresa.

Receitas estimadas(anual) cenário otimista:

\begin{tabular}{|l|}
\hline \multicolumn{1}{|c|}{ Produtos } \\
\hline Casa \\
\hline Comércio \\
\hline Fábrica \\
\hline \\
\hline \multicolumn{1}{|c|}{ TOTAL } \\
\hline
\end{tabular}

\begin{tabular}{|c|}
\hline Quantidade \\
\hline 20 \\
\hline 8 \\
\hline 5 \\
\hline
\end{tabular}

\begin{tabular}{|c|}
\hline Valor Unit. \\
\hline$R \$ 55.000,00$ \\
\hline$R \$ 389.000,00$ \\
\hline$R \$ 791.000,00$ \\
\hline
\end{tabular}

Receita Prevista

$R \$ 1.100 .000,00$

R\$ $3.112 .000,00$

R\$ $3.955 .000,00$

Custos fixos:

\begin{tabular}{|l|}
\hline \multicolumn{1}{|c|}{ Custos Fixos } \\
\hline Salários \\
\hline Benefícios \\
\hline Encargos \\
\hline Wework \\
\hline Celular \\
\hline Manut. Material \\
\hline Marketing Ações \\
\hline Marketing Sociais \\
\hline Pró Labore \\
\hline
\end{tabular}

\begin{tabular}{|c|c|c|c|}
\hline \multicolumn{2}{|r|}{ Mensal } & \multicolumn{2}{|r|}{ Anual } \\
\hline $\mathrm{R} \$$ & $9.100,00$ & $\mathrm{R} \$$ & $109.200,00$ \\
\hline $\mathrm{R} \$$ & $2.871,00$ & $\mathrm{R} \$$ & $34.452,00$ \\
\hline $\mathrm{R} \$$ & $6.370,00$ & $\mathrm{R} \$$ & $76.440,00$ \\
\hline $\mathrm{R} \$$ & $1.800,00$ & $\mathrm{R} \$$ & $21.600,00$ \\
\hline $\mathrm{R} \$$ & 300,00 & $\mathrm{R} \$$ & $3.600,00$ \\
\hline $\mathrm{R} \$$ & 100,00 & $\mathrm{R} \$$ & $1.200,00$ \\
\hline $\mathrm{R} \$$ & 800,00 & $\mathrm{R} \$$ & $9.600,00$ \\
\hline $\mathrm{R} \$$ & 500,00 & $\mathrm{R} \$$ & $6.000,00$ \\
\hline $\mathrm{R} \$$ & $3.000,00$ & $\mathrm{R} \$$ & $36.000,00$ \\
\hline $\mathbf{R} \$$ & $24.841,00$ & $\mathbf{R} \$$ & $298.092,00$ \\
\hline
\end{tabular}


Custos Variáveis no cenário otimista:

\begin{tabular}{|c|c|c|}
\hline Custos Variáveis & Mensal & Anual \\
\hline Fornecedores & $\mathrm{R} \$ 375.000,00$ & $\mathrm{R} \$ 4.500 .000,00$ \\
\hline
\end{tabular}

\begin{tabular}{|c|c|c|c|c|c|c|}
\hline \multirow[b]{2}{*}{ Receita Bruta Operacional } & \multicolumn{2}{|c|}{ Ano 1} & Ano 2 & Ano 3 & Ano 4 & Ano 5 \\
\hline & $\mathbf{R} \$$ & $8.945 .000,00$ & $\mathrm{R} \$ \quad 9.839 .500,00$ & $R \$ 10.823 .450,00$ & $R \$ 11.905 .795,00$ & $R \$ 13.096 .374,50$ \\
\hline Faturamento Anual & $\mathrm{R} \$$ & $8.945 .000,00$ & $\mathrm{R} \$ \quad 9.839 .500,00$ & $\mathrm{R} \$ 10.823 .450,00$ & $\mathrm{R} \$ 11.905 .795,00$ & $\mathrm{R} \$ 13.096 .374,50$ \\
\hline Impostos & & $(3.555 .637,50)$ & $(3.911 .201,25)$ & $(4.302 .321,38)$ & $(4.732 .553,51)$ & $(5.205 .808,86)$ \\
\hline Imposto sobre importação & & $(894.500,00)$ & $(983.950,00)$ & $(1.082 .345,00)$ & $(1.190 .579,50)$ & $(1.309 .637,45)$ \\
\hline $\begin{array}{l}\text { Imposto sobre produto } \\
\text { Industrializado }\end{array}$ & & 0,00 & 0,00 & 0,00 & 0,00 & 0,00 \\
\hline PIS & & $(187.845,00)$ & $(206.629,50)$ & $(227.292,45)$ & $(250.021,70)$ & $(275.023,86)$ \\
\hline COFINS & & $(863.192,50)$ & $(949.511,75)$ & $(1.044 .462,93)$ & $(1.148 .909,22)$ & $(1.263 .800,14)$ \\
\hline ICMS & & $(1.610 .100,00)$ & $(1.771 .110,00)$ & $(1.948 .221,00)$ & $(2.143 .043,10)$ & $(2.357 .347,41)$ \\
\hline Receita Líquida & $\mathbf{R} \$$ & $5.389 .362,50$ & $\mathrm{R} \$ \quad 5.928 .298,75$ & $\mathrm{R} \$ \quad 6.521 .128,63$ & $\mathrm{R} \$ \quad 7.173 .241,49$ & $\mathrm{R} \$ \quad 7.890 .565,64$ \\
\hline Custos Variáveis & & $(4.930 .000,00)$ & $(5.423 .000,00)$ & $(5.965 .300,00)$ & $(6.561 .830,00)$ & $(7.218 .013,00)$ \\
\hline Fornecedores & & $(4.930 .000,00)$ & $(5.423 .000,00)$ & $(5.965 .300,00)$ & $(6.561 .830,00)$ & $(7.218 .013,00)$ \\
\hline Margem de Contribuição & $\mathbf{R} \$$ & $459.362,50$ & $505.298,75$ & $555.828,63$ & $611.411,49$ & $672.552,64$ \\
\hline Custos Fixos & & $(310.092,00)$ & \begin{tabular}{|l|}
$-\mathrm{R} \$$ \\
$282.730,94$ \\
\end{tabular} & $319.212,35$ & $319.212,35$ & $296.411,47$ \\
\hline Salários & & $(109.200,00)$ & $(99.564,71)$ & $(112.411,76)$ & $(112.411,76)$ & $(104.382,35)$ \\
\hline Benefícios & & $(34.452,00)$ & $(31.412,12)$ & $(35.465,29)$ & $(35.465,29)$ & $(32.932,06)$ \\
\hline Encargos & & $(76.440,00)$ & $(69.695,29)$ & $(78.688,24)$ & $(78.688,24)$ & $(73.067,65)$ \\
\hline Wework & & $(21.600,00)$ & $(19.694,12)$ & $(22.235,29)$ & $(22.235,29)$ & $(20.647,06)$ \\
\hline Celular & & $(3.600,00)$ & $(3.282,35)$ & $(3.705,88)$ & $(3.705,88)$ & $(3.441,18)$ \\
\hline Manut. Material & & $(1.200,00)$ & $(1.094,12)$ & $(1.235,29)$ & $(1.235,29)$ & $(1.147,06)$ \\
\hline Marketing Ações & & $(9.600,00)$ & $(8.752,94)$ & $(9.882,35)$ & $(9.882,35)$ & $(9.176,47)$ \\
\hline Marketing Sociais & & $(6.000,00)$ & $(5.470,59)$ & $(6.176,47)$ & $(6.176,47)$ & $(5.735,29)$ \\
\hline Pró-Labore & & $(48.000,00)$ & $(43.764,71)$ & $(49.411,76)$ & $(49.411,76)$ & $(45.882,35)$ \\
\hline Depreciação & & $(1.320,00)$ & $(1.203,53)$ & $(1.358,82)$ & $(1.358,82)$ & $(1.261,76)$ \\
\hline
\end{tabular}




\begin{tabular}{|c|r|r|r|r|r|} 
Resultado operacional & $147.950,50$ & $\mathbf{2 2 1 . 3 6 4 , 2 8}$ & $\mathbf{2 3 5 . 2 5 7 , 4 5}$ & $\mathbf{2 9 0 . 8 4 0 , 3 1}$ & $\mathbf{3 7 4 . 8 7 9 , 4 0}$ \\
\hline IR e CSLL & - & - & - & - & - \\
\hline Resultado & $147.950,50$ & $221.364,28$ & $\mathbf{2 3 5 . 2 5 7 , 4 5}$ & $\mathbf{2 9 0 . 8 4 0 , 3 1}$ & $\mathbf{3 7 4 . 8 7 9 , 4 0}$ \\
\hline
\end{tabular}

exercício no cenário otimista com crescimento de $10 \%$ nas vendas anualmente:

No cenário realista as premissas de receitas diminuem se comparadas ao cenário otimista, podemos observar na tabela a seguir os números referentes a quantidade de projetos e receitas previstas para esse cenário:

\begin{tabular}{|l|}
\hline \multicolumn{1}{|c|}{ Produtos } \\
\hline Casa \\
\hline Comércio \\
\hline Fábrica \\
\hline \multicolumn{1}{|c|}{ TOTAL } \\
\hline
\end{tabular}

\begin{tabular}{|c|}
\hline Quantidade \\
\hline 16 \\
\hline 7 \\
\hline 4 \\
\hline
\end{tabular}

\begin{tabular}{|c|}
\hline Valor Unit. \\
\hline$R \$ 55.000,00$ \\
\hline$R \$ 389.000,00$ \\
\hline$R \$ 791.000,00$ \\
\hline \\
\hline
\end{tabular}

Receita Prevista

$R \$ 880.000,00$

$\mathrm{R} \$ 2.723 .000,00$

R\$ $3.164 .000,00$

R\$ $6.767 .000,00$ 
Os custos fixos se mantém iguais, e o crescimento de $10 \%$ ao ano também, os custos variáveis mudam e estão descritos na DRE do cenário realista na tabela a seguir:

\begin{tabular}{|c|c|c|c|c|c|}
\hline & Ano 1 & Ano 2 & Ano 3 & Ano 4 & Ano 5 \\
\hline $\begin{array}{l}\text { Receita Bruta } \\
\text { Operacional }\end{array}$ & \begin{tabular}{|l|}
$\mathrm{R} \$$ \\
$6.767 .000,00$ \\
\end{tabular} & \begin{tabular}{|l}
$\mathrm{R} \$$ \\
$7.443 .700,00$ \\
\end{tabular} & $\begin{array}{l}\mathrm{R} \$ \\
8.188 .070,00 \\
\end{array}$ & \begin{tabular}{|l|}
$\mathrm{R} \$$ \\
$9.006 .877,00$ \\
\end{tabular} & \begin{tabular}{|l|}
$\mathrm{R} \$$ \\
$9.907 .564,70$ \\
\end{tabular} \\
\hline Faturamento Anual & \begin{tabular}{|l}
$\mathrm{R} \$$ \\
$6.767 .000,00$
\end{tabular} & $\begin{array}{l}\mathrm{R} \$ \\
7.443 .700,00\end{array}$ & $\begin{array}{l}\mathrm{R} \$ \\
8.188 .070,00\end{array}$ & $\begin{array}{l}\mathrm{R} \$ \\
9.006 .877,00\end{array}$ & \begin{tabular}{|l|}
$\mathrm{R} \$$ \\
$9.907 .564,70$
\end{tabular} \\
\hline Impostos & $(2.689 .882,50)$ & $(2.958 .870,75)$ & $(3.254 .757,83)$ & $(3.580 .233,61)$ & $(3.938 .256,97)$ \\
\hline Imposto sobre importação & $(676.700,00)$ & $(744.370,00)$ & $(818.807,00)$ & $(900.687,70)$ & $(990.756,47)$ \\
\hline $\begin{array}{l}\text { Imposto sobre produto } \\
\text { industrializado }\end{array}$ & 0,00 & 0,00 & 0,00 & 0,00 & 0,00 \\
\hline PIS & $(142.107,00)$ & $(156.317,70)$ & $(171.949,47)$ & $(189.144,42)$ & $(208.058,86)$ \\
\hline COFINS & $(653.015,50)$ & $(718.317,05)$ & $(790.148,76)$ & $(869.163,63)$ & $(956.079,99)$ \\
\hline ICMS & $(1.218 .060,00)$ & $(1.339 .866,00)$ & $(1.473 .852,60)$ & $(1.621 .237,86)$ & $(1.783 .361,65)$ \\
\hline Receita Líquida & \begin{tabular}{|l|} 
R\$ \\
4.077.117,50 \\
\end{tabular} & \begin{tabular}{|l}
$\mathrm{R} \$$ \\
$4.484 .829,25$ \\
\end{tabular} & $\begin{array}{l}\mathrm{R} \$ \\
4.933 .312,18 \\
\end{array}$ & \begin{tabular}{|l|}
$\mathrm{R} \$$ \\
$\mathbf{5 . 4 2 6 . 6 4 3 , 3 9}$ \\
\end{tabular} & \begin{tabular}{|l} 
R\$ \\
5.969.307,73 \\
\end{tabular} \\
\hline Custos Variáveis & $(3.729 .000,00)$ & $(4.101 .900,00)$ & $(4.512 .090,00)$ & $(4.963 .299,00)$ & $(5.459 .628,90)$ \\
\hline Fornecedores & $(3.729 .000,00)$ & $(4.101 .900,00)$ & $(4.512 .090,00)$ & $(4.963 .299,00)$ & $(5.459 .628,90)$ \\
\hline Margem de Contribuição & \begin{tabular}{|l|}
$\mathrm{R} \$$ \\
$\mathbf{3 4 8 . 1 1 7 , 5 0}$ \\
\end{tabular} & \begin{tabular}{|l}
$\mathrm{R} \$$ \\
$382.929,25$ \\
\end{tabular} & $\begin{array}{l}\mathrm{R} \$ \\
421.222,18 \\
\end{array}$ & \begin{tabular}{|l|}
$R \$$ \\
$463.344,39$ \\
\end{tabular} & \begin{tabular}{|l|}
$\mathrm{R} \$$ \\
$509.678,83$ \\
\end{tabular} \\
\hline Custos Fixos & $(310.092,00)$ & \begin{tabular}{|l|}
$-\mathrm{R} \$$ \\
$282.730,94$ \\
\end{tabular} & $\begin{array}{l}-\mathrm{R} \$ \\
319.212,35\end{array}$ & \begin{tabular}{|l}
$-\mathrm{R} \$$ \\
$319.212,35$ \\
\end{tabular} & \begin{tabular}{|l|}
$-\mathrm{R} \$$ \\
$296.411,47$ \\
\end{tabular} \\
\hline Salários & $(109.200,00)$ & $(99.564,71)$ & $(112.411,76)$ & $(112.411,76)$ & $(104.382,35)$ \\
\hline Benefícios & $(34.452,00)$ & $(31.412,12)$ & $(35.465,29)$ & $(35.465,29)$ & $(32.932,06)$ \\
\hline Encargos & $(76.440,00)$ & $(69.695,29)$ & $(78.688,24)$ & $(78.688,24)$ & $(73.067,65)$ \\
\hline Wework & $(21.600,00)$ & $(19.694,12)$ & $(22.235,29)$ & $(22.235,29)$ & $(20.647,06)$ \\
\hline Celular & $(3.600,00)$ & $(3.282,35)$ & $(3.705,88)$ & $(3.705,88)$ & $(3.441,18)$ \\
\hline Manut. Material & $(1.200,00)$ & $(1.094,12)$ & $(1.235,29)$ & $(1.235,29)$ & $(1.147,06)$ \\
\hline Marketing Ações & $(9.600,00)$ & $(8.752,94)$ & $(9.882,35)$ & $(9.882,35)$ & $(9.176,47)$ \\
\hline Marketing Sociais & $(6.000,00)$ & $(5.470,59)$ & $(6.176,47)$ & $(6.176,47)$ & $(5.735,29)$ \\
\hline
\end{tabular}




\begin{tabular}{|c|r|r|r|r|r|} 
Pró-Labore & $(48.000,00)$ & $(43.764,71)$ & $(49.411,76)$ & $(49.411,76)$ & $(45.882,35)$ \\
\hline Depreciação & $(1.320,00)$ & $(1.203,53)$ & $(1.358,82)$ & $(1.358,82)$ & $(1.261,76)$ \\
\hline Resultado operacional & $\mathbf{3 6 . 7 0 5 , 5 0}$ & $\mathbf{9 8 . 9 9 4 , 7 8}$ & $\mathbf{1 0 0 . 6 5 1 , 0 0}$ & $\mathbf{1 4 2 . 7 7 3 , 2 2}$ & $\mathbf{2 1 2 . 0 0 5 , 6 0}$ \\
\hline IR e CSLL & - & - & - & - & - \\
\hline Resultado & $\mathbf{3 6 . 7 0 5 , 5 0}$ & $\mathbf{9 8 . 9 9 4 , 7 8}$ & $\mathbf{1 0 0 . 6 5 1 , 0 0}$ & $\mathbf{1 4 2 . 7 7 3 , 2 2}$ & $\mathbf{2 1 2 . 0 0 5 , 6 0}$ \\
\hline
\end{tabular}

Para traçar o cenário pessimista, manteve-se o crescimento de $10 \%$ ao ano, porém o volume de vendas foi diminuído como demonstrado nas tabelas. A seguir, as receitas estimadas:
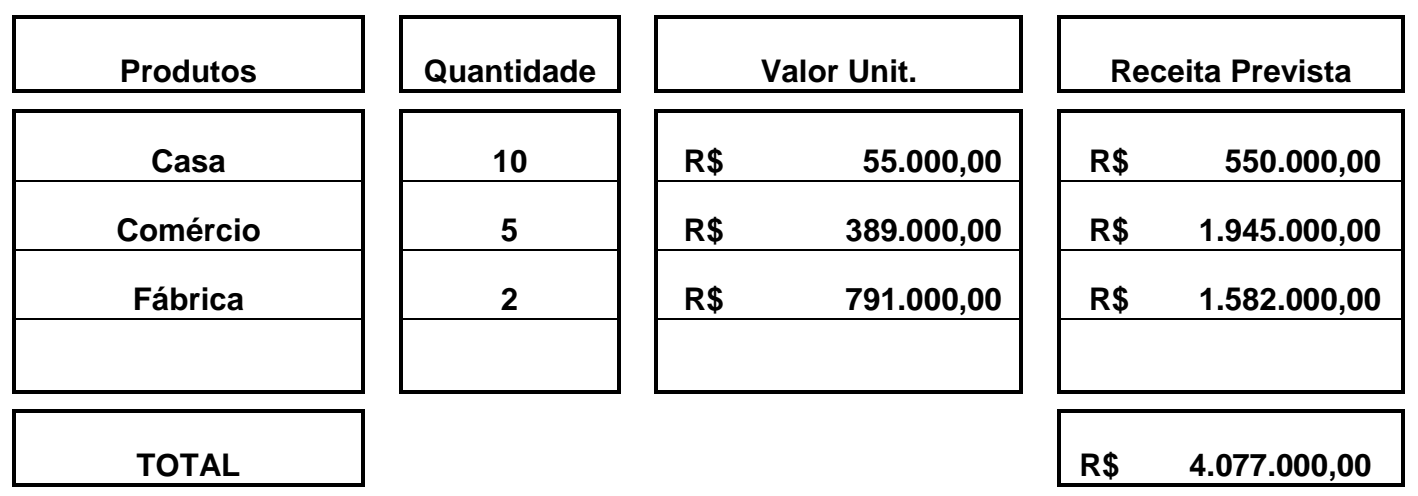

Os custos fixos se mantiveram iguais porem os custos variáveis diminuíram com a queda nas vendas:

\begin{tabular}{|c|c|c|c|}
\hline \multicolumn{2}{|c|}{ Custo Material } & \multicolumn{2}{|c|}{ Resultado } \\
\hline $\mathrm{R} \$$ & $310.000,00$ & $\mathrm{R} \$$ & $240.000,00$ \\
\hline $\mathrm{R} \$$ & $1.075 .000,00$ & $\mathrm{R} \$$ & $870.000,00$ \\
\hline $\mathrm{R} \$$ & $864.000,00$ & $\mathrm{R} \$$ & $718.000,00$ \\
\hline $\mathbf{R} \$$ & $2.249 .000,00$ & $\mathbf{R} \mathbf{S}$ & $1.828 .000,00$ \\
\hline
\end{tabular}


A tabela abaixo mostra a DRE no cenário pessimista, apresentando resultado positivo apenas no $5^{\circ}$ ano de operação:

\begin{tabular}{|c|c|c|c|c|c|}
\hline & Ano 1 & Ano 2 & Ano 3 & Ano 4 & Ano 5 \\
\hline $\begin{array}{l}\text { Receita Bruta } \\
\text { Operacional }\end{array}$ & \begin{tabular}{|l|}
$\mathrm{R} \$$ \\
$4.077 .000,00$ \\
\end{tabular} & \begin{tabular}{|l|}
$\mathrm{R} \$$ \\
$4.484 .700,00$ \\
\end{tabular} & \begin{tabular}{|l|}
$R \$$ \\
$4.933 .170,00$ \\
\end{tabular} & $\begin{array}{l}\mathrm{R} \$ \\
5.426 .487,00\end{array}$ & \begin{tabular}{|l|}
$\mathrm{R} \$$ \\
$5.969 .135,70$
\end{tabular} \\
\hline Faturamento Anual & \begin{tabular}{|l|}
$\mathrm{R} \$$ \\
$4.077 .000,00$ \\
\end{tabular} & \begin{tabular}{|l|}
$\mathrm{R} \$$ \\
$4.484 .700,00$ \\
\end{tabular} & \begin{tabular}{|l|}
$\mathrm{R} \$$ \\
$4.933 .170,00$ \\
\end{tabular} & $\begin{array}{l}\mathrm{R} \$ \\
5.426 .487,00\end{array}$ & \begin{tabular}{|l|}
$\mathrm{R} \$$ \\
$5.969 .135,70$ \\
\end{tabular} \\
\hline Impostos & $(1.620 .607,50)$ & $(1.782 .668,25)$ & $(1.960 .935,08)$ & $(2.157 .028,58)$ & $(2.372 .731,44)$ \\
\hline Imposto sobre importação & $(407.700,00)$ & $(448.470,00)$ & $(493.317,00)$ & $(542.648,70)$ & $(596.913,57)$ \\
\hline $\begin{array}{l}\text { Imposto sobre produto } \\
\text { industrializado }\end{array}$ & 0,00 & 0,00 & 0,00 & 0,00 & 0,00 \\
\hline PIS & $(85.617,00)$ & $(94.178,70)$ & $(103.596,57)$ & $(113.956,23)$ & $(125.351,85)$ \\
\hline COFINS & $(393.430,50)$ & $(432.773,55)$ & $(476.050,91)$ & $(523.656,00)$ & $(576.021,60)$ \\
\hline ICMS & $(733.860,00)$ & $(807.246,00)$ & $(887.970,60)$ & $(976.767,66)$ & $(1.074 .444,43)$ \\
\hline Receita Líquida & \begin{tabular}{|l|}
$\mathrm{R} \$$ \\
$2.456 .392,50$ \\
\end{tabular} & \begin{tabular}{|l|}
$\mathrm{R} \$$ \\
$2.702 .031,75$ \\
\end{tabular} & \begin{tabular}{|l|}
$\mathrm{R} \$$ \\
$2.972 .234,93$ \\
\end{tabular} & $\begin{array}{l}\mathrm{R} \$ \\
3.269 .458,42 \\
\end{array}$ & \begin{tabular}{|l|}
$\mathrm{R} \$$ \\
$3.596 .404,26$ \\
\end{tabular} \\
\hline Custos Variáveis & $(2.249 .000,00)$ & $(2.473 .900,00)$ & $(2.721 .290,00)$ & $(2.993 .419,00)$ & $(3.292 .760,90)$ \\
\hline Fornecedores & $(2.249 .000,00)$ & $(2.473 .900,00)$ & $(2.721 .290,00)$ & $(2.993 .419,00)$ & $(3.292 .760,90)$ \\
\hline Margem de Contribuição & \begin{tabular}{|l|}
$\mathrm{R} \$$ \\
$207.392,50$ \\
\end{tabular} & \begin{tabular}{|l|}
$\mathrm{R} \$$ \\
$228.131,75$ \\
\end{tabular} & \begin{tabular}{|l|}
$R \$$ \\
$250.944,93$ \\
\end{tabular} & \begin{tabular}{|l|}
$R \$$ \\
$276.039,42$ \\
\end{tabular} & \begin{tabular}{|l|}
$\mathrm{R} \$$ \\
$303.643,36$ \\
\end{tabular} \\
\hline Custos Fixos & $(310.092,00)$ & \begin{tabular}{|l|}
$-\mathrm{R} \$$ \\
$282.730,94$ \\
\end{tabular} & \begin{tabular}{|l|}
$-\mathrm{R} \$$ \\
$319.212,35$ \\
\end{tabular} & \begin{tabular}{|l|}
$-\mathrm{R} \$$ \\
$319.212,35$ \\
\end{tabular} & \begin{tabular}{|l|}
$-\mathrm{R} \$$ \\
$296.411,47$ \\
\end{tabular} \\
\hline Salários & $(109.200,00)$ & $(99.564,71)$ & $(112.411,76)$ & $(112.411,76)$ & $(104.382,35)$ \\
\hline Benefícios & $(34.452,00)$ & $(31.412,12)$ & $(35.465,29)$ & $(35.465,29)$ & $(32.932,06)$ \\
\hline Encargos & $(76.440,00)$ & $(69.695,29)$ & $(78.688,24)$ & $(78.688,24)$ & $(73.067,65)$ \\
\hline Wework & $(21.600,00)$ & $(19.694,12)$ & $(22.235,29)$ & $(22.235,29)$ & $(20.647,06)$ \\
\hline Celular & $(3.600,00)$ & $(3.282,35)$ & $(3.705,88)$ & $(3.705,88)$ & $(3.441,18)$ \\
\hline Manut. Material & $(1.200,00)$ & $(1.094,12)$ & $(1.235,29)$ & $(1.235,29)$ & $(1.147,06)$ \\
\hline Marketing Ações & $(9.600,00)$ & $(8.752,94)$ & $(9.882,35)$ & $(9.882,35)$ & $(9.176,47)$ \\
\hline Marketing Sociais & $(6.000,00)$ & $(5.470,59)$ & $(6.176,47)$ & $(6.176,47)$ & $(5.735,29)$ \\
\hline Pró-Labore & $(48.000,00)$ & $(43.764,71)$ & $(49.411,76)$ & $(49.411,76)$ & $(45.882,35)$ \\
\hline Depreciação & $(1.320,00)$ & $(1.203,53)$ & $(1.358,82)$ & $(1.358,82)$ & $(1.261,76)$ \\
\hline
\end{tabular}




\begin{tabular}{|c|r|r|r|r|r|} 
Resultado operacional & $(104.019,50)$ & $(55.802,72)$ & $(69.626,25)$ & $(44.531,76)$ & $5.970,12$ \\
\hline IR e CSLL & - & - & - & - & - \\
\hline Resultado & $(104.019,50)$ & $(55.802,72)$ & $(69.626,25)$ & $(44.531,76)$ & $5.970,12$ \\
\hline
\end{tabular}

\subsubsection{CUSTOS E TRIBUTAÇÃO}

O gerenciamento de custos exige que o gestor tenha o mínimo de conhecimento na área contábil, também é imprescindível que ele conheça a empresa, o mercado, e ainda os indivíduos que ali realizam suas funções, no caso de uma organização empresarial, haja vista que é de suma relevância que os aspectos de gastos, compras, vendas, estoque, enfim, todos esses elementos que fazem parte de uma análise de custos, também sejam contemplados, considerando que nem sempre o mais barato é o que melhor irá atender à equipe.

Os recursos, dentro das organizações, são os instrumentos utilizados para se alcançar os objetivos pré-estabelecidos pelos gestores da instituição a fim de se cumprir com a missão da empresa dentro da sociedade.

Os Recursos Organizacionais são os vários meios que as instituições possuem para atingirem seus objetivos. São os bens ou serviços utilizados nas atividades organizacionais. Quando se fala em recursos não estamos nos referido apenas em dinheiro, mas nos referimos às matérias primas utilizadas nas produções, nos serviços prestados pelas organizações, matérias, equipamentos e colaboradores. (SOUZA e LIMA, 2008, p. 17).

Sendo assim, existem diversos tipos de recursos dentro de uma organização, no entanto, os mais percebidos nas literaturas são: Humanos, que consistem nas pessoas, em diferentes níveis institucionais, que trabalham para o cumprimento das metas a fim de propiciar o bom andamento das atividades da organização; Financeiros que, por sua vez, consistem no capital propriamente dito, utilizado para financiar todas as ações da instituição e os Materiais que vem a ser o ambiente no qual está inserida a instituição, bem como, os serviços realizados e oferecidos pela 
mesma para seus usuários. Nesse sentido é fundamental que os recursos estejam em conformidade com as necessidades da organização, considerando que "também denominada orçamento, a estimativa de custos de um projeto deve levar em consideração três informações: custo unitário de cada recurso utilizado (humano e material), duração das atividades e custos indiretos." (MAXIMIANO, 2002, apud CHICARINO, 2005, p. 25).

Os custos, portanto, muitas vezes podem ser superior ao que os gestores imaginam, mas não porque os produtos de custo mais elevado seja, necessariamente de maior qualidade do que os mais baratos, mas sim porque a contratação de mão-de-obra capacitada, a promoção da qualificação e, também o uso de equipamentos atualizados, se tornam uma necessidade para a área de tecnologia da informação, principalmente quando se fala no cumprimento de prazos, e a busca pela garantia do custo $\mathrm{x}$ benefício mais favoráveis, tanto para as empresas, quanto para os consumidores.

Os tributos incidentes na operação de importação e venda de células fotovoltaicas estão descritos na tabela a seguir:

\begin{tabular}{|l|r|}
\hline \multicolumn{1}{|c|}{ Tributos } & \multicolumn{1}{c|}{ Valor } \\
\hline \hline II & $10,0 \%$ \\
\hline IPI & $0,0 \%$ \\
\hline PIS & $2,1 \%$ \\
\hline COFINS & $9,7 \%$ \\
\hline ICMS & $18,0 \%$ \\
\hline
\end{tabular}

Para fins de imposto de renda, não foi encontrada uma alíquota referente ao serviço oferecido, em algumas consultas foi possível identificar isenção da cobrança, em outras consultas foi identificado incentivo fiscal com descontos oferecidos de $75 \%$ da alíquota de $15 \%$ e em outras consultas foi possível ver a alíquota integral de $15 \%$. Portanto o imposto de renda não será levado em consideração no plano financeiro. 


\subsubsection{FLUXO DE CAIXA}

O fluxo de caixa consiste em um dos principais componentes da administração financeira e orçamentária, visto que o mesmo ilustra, de maneira clara e objetiva todas as operações realizadas pela empresa ou pelo indivíduo.

[...] A demonstração da administração de caixa indica, no mínimo, as alterações ocorridas no exercício no saldo de caixa e equivalente de caixa, segregadas em fluxos das operações, dos financiamentos e investimentos. Essa demonstração será obtida de forma direta (através da movimentação do caixa e equivalentes de caixa) ou de forma indireta (com base no lucro/prejuízo do exercício) [...]. (MARION, 2012 apud MARTINS, 2014, p. 32).

Deste modo, um modelo estruturado de gestão de caixa possibilita o reconhecimento do andamento das atividades financeiras da organização e, mais do que isso, também proporciona a visualização de melhores oportunidades de intervenção, uma vez que as movimentações de caixa permitem uma visualização mais ampla de gastos e custos orçamentários.

A tabela abaixo demonstra o fluxo de caixa projetado para 5 anos no cenário otimista:

\begin{tabular}{|c|c|c|c|c|c|c|}
\hline & ANO 0 & ANO 1 & ANO 2 & ANO 3 & ANO 4 & ANO 5 \\
\hline SALDO DE CAIXA & $-\quad 177.280,00$ & $68.074,50$ & $110.670,28$ & $299.046,28$ & $538.316,99$ & $856.469,84$ \\
\hline TOTAL DE ENTRADAS & $-\quad 177.280,00$ & $8.167 .000,00$ & $8.983 .700,00$ & $9.882 .070,00$ & $10.870 .277,00$ & $11.957 .304,70$ \\
\hline Receita de vendas & & $8.167 .000,00$ & $8.983 .700,00$ & $9.882 .070,00$ & $10.870 .277,00$ & $11.957 .304,70$ \\
\hline Investimento & $177.280,00$ & - & & & & \\
\hline TOTAL DE SAÍDAS & & - $\quad 8.057 .794,50$ & - $\quad 8.804 .955,22$ & - $\quad 9.693 .694,00$ & - $\quad 10.631 .006,28$ & $-11.639 .151,85$ \\
\hline Impostos e deduções & & $\begin{array}{l}-\quad 3.246 .382,50 \\
\end{array}$ & - $\quad 3.571 .020,75$ & $\begin{array}{l}-\quad 3.928 .122,83 \\
\end{array}$ & $4.320 .935,11$ & $-4.753 .028,62$ \\
\hline Fornecedores & & - $\quad 4.500 .000,00$ & $\begin{array}{l}-\quad 4.950 .000,00 \\
\end{array}$ & $\begin{array}{l}-\quad 5.445 .000,00 \\
\end{array}$ & $\begin{array}{l}-\quad 5.989 .500,00 \\
\end{array}$ & $-6.588 .450,00$ \\
\hline Salários & & $109.200,00$ & $99.564,71$ & $112.411,76$ & $112.411,76$ & - $\quad 104.382,35$ \\
\hline Benefícios & & $34.452,00$ & $31.412,12$ & $35.465,29$ & $35.465,29$ & $32.932,06$ \\
\hline Encargos & & $76.440,00$ & $69.695,29$ & $78.688,24$ & $78.688,24$ & $73.067,65$ \\
\hline Wework & & $21.600,00$ & $19.694,12$ & $22.235,29$ & $22.235,29$ & $20.647,06$ \\
\hline Celular & & $3.600,00$ & $3.282,35$ & $3.705,88$ & $3.705,88$ & $3.441,18$ \\
\hline Manut. Material & & $1.200,00$ & $1.094,12$ & $1.235,29$ & $1.235,29$ & $1.147,06$ \\
\hline Marketing Ações & & $9.600,00$ & $8.752,94$ & $9.882,35$ & $9.882,35$ & $9.176,47$ \\
\hline Marketing Sociais & & $6.000,00$ & $5.470,59$ & $6.176,47$ & $6.176,47$ & $5.735,29$ \\
\hline Pró Labore & & $48.000,00$ & $43.764,71$ & $49.411,76$ & $49.411,76$ & $45.882,35$ \\
\hline
\end{tabular}




\begin{tabular}{|c|c|c|c|c|c|c|c|c|c|}
\hline Depreciação & & - & $1.320,00$ & - & $1.203,53$ & $1.358,82$ & - & $1.358,82$ & $1.261,76$ \\
\hline SALDO DO PERÍODO & $-\mathrm{R} \$ 177.280,00$ & $\mathrm{R} \$$ & $109.205,50$ & $\mathrm{R} \$$ & $178.744,78$ & \begin{tabular}{|l}
$R \$$ \\
$188.376,00$
\end{tabular} & $\mathrm{R} \S$ & $239.270,72$ & $\mathrm{R} \$ 318.152,85$ \\
\hline
\end{tabular}

Também foi traçado o fluxo para o cenário realista do projeto, a tabela a seguir demonstra os resultados:

\begin{tabular}{|c|c|c|c|c|c|c|}
\hline & ANO 0 & ANO 1 & ANO 2 & ANO 3 & ANO 4 & ANO 5 \\
\hline SALDO DE CAIXA & $-\quad 177.280,00$ & $140.574,50$ & $41.579,72$ & $59.071,28$ & $201.844,49$ & $413.850,09$ \\
\hline TOTAL DE ENTRADAS & $\begin{array}{l}-\quad 177.280,00 \\
\end{array}$ & $6.767 .000,00$ & 7.443.700,00 & 8.188.070,00 & $9.006 .877,00$ & $9.907 .564,70$ \\
\hline Receita de vendas & & $6.767 .000,00$ & $7.443 .700,00$ & $8.188 .070,00$ & $9.006 .877,00$ & $9.907 .564,70$ \\
\hline Investimento & $177.280,00$ & & & & & \\
\hline TOTAL DE SAÍDAS & & $-\quad 6.730 .294,50$ & - $\quad 7.344 .705,22$ & - $\quad 8.087 .419,00$ & $8.864 .103,78$ & $\begin{array}{l}-\quad 9.695 .559,10 \\
\end{array}$ \\
\hline Impostos e deduções & & $-\quad 2.689 .882,50$ & $\begin{array}{l}-\quad 2.958 .870,75 \\
\end{array}$ & $\begin{array}{l}-\quad 3.254 .757,83 \\
\end{array}$ & $\begin{array}{l}-\quad 3.580 .233,61 \\
\end{array}$ & $\begin{array}{l}-\quad 3.938 .256,97 \\
\end{array}$ \\
\hline Fornecedores & & - $\quad 3.729 .000,00$ & $\begin{array}{l}-\quad 4.101 .900,00 \\
\end{array}$ & $\begin{array}{l}-\quad 4.512 .090,00 \\
\end{array}$ & 4.963.299,00 & $\begin{array}{l}-\quad 5.459 .628,90 \\
\end{array}$ \\
\hline Salários & & $109.200,00$ & $99.564,71$ & $112.411,76$ & $112.411,76$ & $104.382,35$ \\
\hline Benefícios & & $34.452,00$ & $31.412,12$ & $35.465,29$ & $35.465,29$ & $32.932,06$ \\
\hline Encargos & & $76.440,00$ & $69.695,29$ & $78.688,24$ & $78.688,24$ & $73.067,65$ \\
\hline Wework & & $21.600,00$ & $19.694,12$ & $22.235,29$ & $22.235,29$ & $20.647,06$ \\
\hline Celular & & $3.600,00$ & $3.282,35$ & $3.705,88$ & $3.705,88$ & $3.441,18$ \\
\hline Manut. Material & & $1.200,00$ & $1.094,12$ & $1.235,29$ & $1.235,29$ & $1.147,06$ \\
\hline Marketing Ações & & $9.600,00$ & $8.752,94$ & $9.882,35$ & $9.882,35$ & $9.176,47$ \\
\hline Marketing Sociais & & $6.000,00$ & $5.470,59$ & $6.176,47$ & $6.176,47$ & $5.735,29$ \\
\hline Pró Labore & & $48.000,00$ & $43.764,71$ & $49.411,76$ & $49.411,76$ & $45.882,35$ \\
\hline Depreciação & & -1320 & $1.203,53$ & $1.358,82$ & $1.358,82$ & $1.261,76$ \\
\hline SALDO DO PERÍODO & $-\mathrm{R} \$ 177.280,00$ & $\mathrm{R} \$ \quad 36.705,50$ & $\mathrm{R} \$ \quad 98.994,78$ & $\mathrm{R} \$ 100.651,00$ & $142.773,22$ & $\mathrm{R} \$ \quad 212.005,60$ \\
\hline
\end{tabular}

A tabela a seguir demonstra o fluxo num cenário pessimista:

\begin{tabular}{|c|c|c|c|c|c|c|}
\hline & ANO 0 & ANO 1 & ANO 2 & ANO 3 & ANO 4 & ANO 5 \\
\hline SALDO DE CAIXA & $-\quad 177.280,00$ & $281.299,50$ & $159.822,22$ & $125.428,97$ & $114.158,01$ & $38.561,64$ \\
\hline TOTAL DE ENTRADAS & $-\quad 177.280,00$ & $4.077 .000,00$ & $4.484 .700,00$ & 4.933.170,00 & $5.426 .487,00$ & $5.969 .135,70$ \\
\hline Receita de vendas & & $4.077 .000,00$ & $4.484 .700,00$ & 4.933.170,00 & $5.426 .487,00$ & $5.969 .135,70$ \\
\hline Investimento & $177.280,00$ & - & & & & \\
\hline TOTAL DE SAÍDAS & & $-\quad 4.181 .019,50$ & $-\quad 4.540 .502,72$ & $\begin{array}{l}-\quad 5.002 .796,25 \\
\end{array}$ & $5.471 .018,76$ & - 5.963.165,58 \\
\hline Impostos e deduções & & $-\quad 1.620 .607,50$ & $\begin{array}{l}-\quad 1.782 .668,25 \\
\end{array}$ & $\begin{array}{l}-\quad 1.960 .935,08 \\
\end{array}$ & $2.157 .028,58$ & - 2.372.731,44 \\
\hline Fornecedores & & $-\quad 2.249 .000,00$ & $\begin{array}{l}-\quad 2.473 .900,00 \\
\end{array}$ & \begin{tabular}{|r|}
$-\quad 2.721 .290,00$ \\
\end{tabular} & 2.993.419,00 & - 3.292.760,90 \\
\hline Salários & & $109.200,00$ & $99.564,71$ & $112.411,76$ & $112.411,76$ & $\begin{array}{l}-\quad 104.382,35 \\
\end{array}$ \\
\hline Benefícios & & $34.452,00$ & $31.412,12$ & $35.465,29$ & $35.465,29$ & $32.932,06$ \\
\hline
\end{tabular}




\begin{tabular}{|l|r|rr|rr|rr|rr|rr|} 
Encargos & & - & $76.440,00$ & - & $69.695,29$ & - & $78.688,24$ & - & $78.688,24$ & - & $73.067,65$ \\
\hline Wework & & - & $21.600,00$ & - & $19.694,12$ & - & $22.235,29$ & - & $22.235,29$ & - & $20.647,06$ \\
\hline Celular & & - & $3.600,00$ & - & $3.282,35$ & - & $3.705,88$ & - & $3.705,88$ & - & $3.441,18$ \\
\hline Manut. Material & & - & $1.200,00$ & - & $1.094,12$ & - & $1.235,29$ & - & $1.235,29$ & - & $1.147,06$ \\
\hline Marketing Ações & & - & $9.600,00$ & - & $8.752,94$ & - & $9.882,35$ & - & $9.882,35$ & - & $9.176,47$ \\
\hline Marketing Sociais & & - & $6.000,00$ & - & $5.470,59$ & - & $6.176,47$ & - & $6.176,47$ & - & $5.735,29$ \\
\hline Pró Labore & & - & $48.000,00$ & - & $43.764,71$ & - & $49.411,76$ & - & $49.411,76$ & - & $45.882,35$ \\
\hline Depreciação & & - & $1.320,00$ & - & $1.203,53$ & - & $1.358,82$ & - & $1.358,82$ & - & $1.261,76$ \\
\hline SALDO DO PERÍODO & $-\mathrm{R} \$ 177.280,00$ & $-\mathrm{R} \$ 104.019,50$ & $-\mathrm{R} \$$ & $55.802,72$ & $-\mathrm{R} \$$ & $69.626,25$ & $-\mathrm{R} \$$ & $44.531,76$ & $\mathrm{R} \$$ & $5.970,12$ \\
\hline
\end{tabular}

\subsubsection{INDICADORES DE VIABILIDADE}

Os benefícios trazidos pelo plano de negócios são intimamente compatíveis, com as necessidades da tecnologia da sustentabilidade, em especial devido ao fato de estimular a elaboração de projetos que primem pelo custo $\mathrm{x}$ benefício, considerem os prazos, também avaliem os riscos, e que incluam a participação de todos os envolvidos no processo, mesmo no decorrer da elaboração do plano o que, por sua vez, já é de extrema relevância, principalmente quando se abordam os aspectos das especificidades que cada colaborador utiliza para desenvolver o seu trabalho, dentro da corporação.

De acordo com Vargas (2003), existem alguns benefícios da gestão de projeto, que devem ser considerados durante o processo de escolha e construção de um plano, a saber:

- Agiliza decisões, uma vez que as informações estão estruturadas e disponibilizadas;

- Aumenta o controle gerencial de todas as fases a serem implantadas, mediante detalhamento das atividades;

- Evita surpresas durante a execução das atividades;

- Antecipa situações desfavoráveis que poderão ser encontradas, para que ações preventivas e corretivas possam ser tomadas antes que essas situações se consolidem como problemas;

- Facilita e orienta revisões da estrutura do projeto, motivadas por modificações no mercado ou na organização, permitindo a adaptação do projeto ao novo contexto;

- Otimiza a alocação de recursos. (VARGAS, 2003, apud CHICARINO, 2005, p. 18).

Desta forma, pode-se compreender que a gestão de projetos favorece a evolução dos planejamentos, e também contribui para que o trabalhe se torne mais 
eficiente, eficaz, e otimizado, por meio da maneira como conduz as atividades diárias de uma organização.

A partir dos dados apresentados nas tabelas anteriores foram obtidos dentro do cenário otimista os valores da Taxa Interna de Retorno de $84 \%$ e o Valor presente líquido positivo. Para o cálculo do VPL foi utilizado a taxa de desconto de $15 \%$ utilizada pelo setor de energia e o payback se deu em 2,6 anos como demonstrado na tabela abaixo:

\begin{tabular}{|l|r|}
\hline TIR & $84 \%$ \\
\hline VPL & $471.680,32$ \\
\hline TMA & $15 \%$ \\
\hline Payback & 2,6 anos \\
\hline
\end{tabular}

No cenário realista a TIR é de 43\% e o VPL positivo no valor de $182.707,07$ reais, o payback do projeto é em 3,7 anos como demonstrado na tabela a seguir:

\begin{tabular}{|l|r|}
\hline TIR & $43 \%$ \\
\hline VPL & $182.707,07$ \\
\hline TMA & $15 \%$ \\
\hline Payback & 3,7 anos \\
\hline
\end{tabular}

No cenário pessimista não foi possível calcular a TIR e o VPL ficou negativo, portanto o projeto se torna inviável nesse cenário como demonstra a tabela:

\begin{tabular}{|l|r|}
\hline TIR & -- \\
\hline VPL & $-378.199,07$ \\
\hline TMA & $15 \%$ \\
\hline Payback & 12,5 anos \\
\hline
\end{tabular}




\section{CONCLUSÃO}

O desenvolvimento do plano de negócios tem como objetivo avaliar a viabilidade do desenvolvimento de uma empresa de energia solar fotovoltaica no mercado brasileiro. Além disso ele permite uma visão clara de todas as operações da empresa e também avaliação em dois cenários tanto no pessimista quando no otimista.

O trabalho desenvolvido demonstra viabilidade no cenário realista onde 0 resultado se mostrou muito satisfatório com o valor presente líquido positivo de $R \$$ $182.707,07$, taxa de retorno de $43 \%$ e payback em 3,7 anos.

Deverão ser observadas todas as mudanças de mercado que surgirão ao longo tempo, novas tecnologias e novas tendências para que possa ser feita a atualização da empresa para se manter competitiva no mercado.

O Brasil possui potencial enorme para a geração de energia solar fotovoltaica e isso deve ser aproveitado. Todo consumidor de energia elétrica deve ter a oportunidade de escolher a forma com que a sua energia é produzida e consumida.

Após o desenvolvimento do plano de negócios da SunFor é possível concluir que a empresa possui boa capacidade de geração de valor e está propensa a riscos de mercado. No cenário pessimista o valor presente líquido negativo recomenda a não efetivação do projeto, mas no cenário otimista os valores acima citados juntamente com as projeções de mercado previstas demonstram o potencial que a empresa possui e ainda indicam um excelente retorno para o investimento. 


\section{REFERÊNCIAS BIBLIOGRÁFICAS}

BRITTO, Antônio Carlos Pereira de. Estudo do Gerenciamento de Projeto Baseado no PMBOK para a Implantação da Gestão da Segurança da Informação e Comunicação na Administração Pública Federal. Brasília: UNB, 2009.

CAMPOS, André Luiz Gonçalves. Uso de Mapas Mentais como ferramenta de Gestão de Projetos em áreas de consultoria de negócios e produtos. IX SEGeT (Simpósio de Excelência em Gestão e Tecnologia), 24 a 26 de outubro de 2012.

CHICARINO, Gustavo Zanardi. O Uso do Mind Map como Ferramenta de Gestão de Projetos em Áreas de Consultoria e Desenvolvimento de Negócios e Produtos. São Paulo: USP, 2005.

COSO (Committee of Sponsoring Organizations of the Treadway Commission). Gerenciamento de Riscos Corporativos: Estrutura integrada. 2007. Disponível em: $<$ https://www.coso.org/Documents/COSO-ERM-Executive-SummaryPortuguese.pdf>. Acesso em 20 de Outubro de 2019.

ENAP. Gerência de Projetos: Teoria e Prática. Brasília: Fundação Escola Nacional de Administração Pública, 2014.

GABRIEL Martha. Marketing na Era Digital. São Paulo: Novatec, 2010.

MARION, José Carlos. Análise das Demonstrações Contábeis. São Paulo: Atlas, 2012.

MARTINS, Amanda. A Utilização das Ferramentas da Gestão Financeira nas Empresas: Análise das Micro e Pequenas Empresas da Cidade de Pato Branco no Sudoeste do Paraná. 2014. 66 f. Trabalho de Conclusão de Curso (Bacharelado em Ciências Contábeis) - Universidade Tecnológica Federal do Paraná, Pato Branco. Disponível em:

$<$ http://repositorio.roca.utfpr.edu.br/jspui/bitstream/1/3350/1/PB COCTB 2014202. pdf>. Acesso em 24 de Outubro de 2019.

MAXIMIANO, Antônio Cesar Amaru. Administração de Projetos. $2^{\underline{a}}$ Edição. São Paulo: Atlas, 2002.

NAKAGAWA, Marcelo. A ferramenta análise SWOT (Clássico): Estratégia e Gestão. Movimento Empreenda: São Paulo, 2011. Disponível em:

$<$ https://m.sebrae.com.br/Sebrae/Portal\%20Sebrae/Anexos/ME Analise-Swot.PDF>. Acesso em 22 de Outubro de 2019.

NASCIMENTO, Valéria Moura. Gerenciamento de Risco em Projetos: Como Transformar Riscos em Vantagem Competitiva. Rio de Janeiro: UVA, 2003.

OSTERWALDER, Alexsander. PIGNEUR, Yves. Business Model Generation Inovação em Modelos de Negócios: Um Manual para Visionários, Inovadores e Revolucionários. Rio de Janeiro: Alta Books, 2011. 
PMI. Um Guia do Conjunto de Conhecimentos em Gerenciamento de Projetos: Guia PMBOK. 2004. Uma Norma Nacional Americana ANSI/PMI 99-001-2004.

ROSS, Jordan Westerfield. Princípios de Administração Financeira. São Paulo: Atlas, 2000.

MARÇAL, Luciana. Plano de Negócios Energia Solar. São Paulo, IBMEC, 2016. SILVA, Antônio Joaquim da. Gestão de Projetos. Florianópolis, SENAI/SC, 2012.

VARGAS, Ricardo Viana. Gerenciamento de Projetos: estabelecendo diferenciais competitivos. Rio de Janeiro: Brassport, 2003. 